\title{
De novo assembly and comparative transcriptome analysis of Monilinia fructicola, Monilinia laxa and Monilinia fructigena, the causal agents of brown rot on stone fruits
}

Rita M. De Miccolis Angelini i (D), Domenico Abate, Caterina Rotolo, Donato Gerin, Stefania Pollastro and Francesco Faretra

\begin{abstract}
Background: Brown rots are important fungal diseases of stone and pome fruits. They are caused by several Monilinia species but M. fructicola, M. laxa and M. fructigena are the most common all over the world. Although they have been intensively studied, the availability of genomic and transcriptomic data in public databases is still scant. We sequenced, assembled and annotated the transcriptomes of the three pathogens using mRNA from germinating conidia and actively growing mycelia of two isolates of opposite mating types per each species for comparative transcriptome analyses.
\end{abstract}

Results: Illumina sequencing was used to generate about 70 million of paired-end reads per species, that were de novo assembled in 33,861 contigs for M. fructicola, 31,103 for M. laxa and 28,890 for M. fructigena. Approximately, $50 \%$ of the assembled contigs had significant hits when blasted against the NCBI non-redundant protein database and top-hits results were represented by Botrytis cinerea, Sclerotinia sclerotiorum and Sclerotinia borealis proteins. More than $90 \%$ of the obtained sequences were complete, the percentage of duplications was always less than $14 \%$ and fragmented and missing transcripts less than 5\%. Orthologous transcripts were identified by tBLASTn analysis using the $B$. cinerea proteome as reference. Comparative transcriptome analyses revealed 65 transcripts over-expressed (FC $\geq 8$ and FDR $\leq 0.05$ ) or unique in M. fructicola, 30 in M. laxa and 31 in M. fructigena. Transcripts were involved in processes affecting fungal development, diversity and host-pathogen interactions, such as plant cell wall-degrading and detoxifying enzymes, zinc finger transcription factors, MFS transporters, cell surface proteins, key enzymes in biosynthesis and metabolism of antibiotics and toxins, and transposable elements.

Conclusions: This is the first large-scale reconstruction and annotation of the complete transcriptomes of $M$. fructicola, M. laxa and M. fructigena and the first comparative transcriptome analysis among the three pathogens revealing differentially expressed genes with potential important roles in metabolic and physiological processes related to fungal morphogenesis and development, diversity and pathogenesis which need further investigations. We believe that the data obtained represent a cornerstone for research aimed at improving knowledge on the population biology, physiology and plant-pathogen interactions of these important phytopathogenic fungi.

Keywords: Transcriptomics, Trinity assembly, RNA-Seq, Plant pathogens, Fungi, Stone fruit disease

\footnotetext{
* Correspondence: ritamilvia.demiccolisangelini@uniba.it

Department of Soil, Plant and Food Sciences - Plant Pathology Section,

University of Bari Aldo Moro, via Amendola 165/A, 70126 Bari, Italy
}

(c) The Author(s). 2018 Open Access This article is distributed under the terms of the Creative Commons Attribution 4.0 International License (http://creativecommons.org/licenses/by/4.0/), which permits unrestricted use, distribution, and reproduction in any medium, provided you give appropriate credit to the original author(s) and the source, provide a link to the Creative Commons license, and indicate if changes were made. The Creative Commons Public Domain Dedication waiver (http://creativecommons.org/publicdomain/zero/1.0/) applies to the data made available in this article, unless otherwise stated. 


\section{Background}

Brown rots are major diseases of stone and pome fruits that can cause severe yield losses during both field production and post-harvest processing [1]. Several species of Monilinia genus are responsible for the diseases, but Monilinia fructicola (G. Winter) Honey (MFRC), Monilinia laxa (Aderh. \& Ruhland) Honey (MLAX) and Monilinia fructigena Honey (MFRG) are the most common species all over the world [1-3]. MLAX and MFRG have been the only ones present in Europe until 2001 when MFRC has been introduced, rapidly spread and become prevalent on the former indigenous species $[4,5]$. Some phenotypic differences in fitness parameters such as growth rate in response to temperature, fungicide sensitivity and virulence have been recorded among the three species [5-7] but the reasons underlying its successfulness have not yet well clarified.

Although the three fungi have been deeply studied, the availability of genomic and transcriptomic data in public databases is still scant. There are only few published studies on the genetic variation in Monilinia species using different molecular markers, i.e. internal transcribed spacer (ITS) $[8,9]$, random amplified polymorphic DNA (RAPD) [6], simple sequence repeat (SSRs) and inter SSR (ISSR) [10, 11], and the characterization of specific genes, such as genes responsible for fungicide resistance [12] or pathogenicity [13].
In this study, we used Illumina sequencing of mRNA from conidia and mycelia of MFRC, MLAX and MFRG to obtain a de novo Trinity-based assembly of their transcriptomes. Orthologous transcripts were identified and compared to detect those apparently unique or differentially expressed in each species.

\section{Methods}

\section{Samples}

Two isolates of opposite mating type per each species, determined by PCR-based mating type assays [14], collected from naturally infected fruits sampled in orchards located in Italy, were used in this study (Table 1). The isolates were grown under different conditions to obtain comprehensive transcriptomes: i) mycelium grown at 21 $\pm 1{ }^{\circ} \mathrm{C}$ on cellophane disks overlaid on potato dextrose agar (infusion from $200 \mathrm{~g}$ peeled and sliced potatoes kept at $60{ }^{\circ} \mathrm{C}$ for $1 \mathrm{~h}, 20 \mathrm{~g}$ dextrose, adjusted at $\mathrm{pH} 6.5$, $20 \mathrm{~g}$ agar Oxoid No. 3, per litre) in the dark for 4 days; ii) mycelium grown as above but in the dark for 2 days and then exposed $12 \mathrm{~h}$ per day to a combination of 2 daylight (Osram L36 W/20) and 2 near-UV (Osram, L36/73) lamps for 2 days; iii) conidia $\left(1 \times 10^{5} \mathrm{~mL}^{-1}\right)$ germinating in malt extract medium (20 g malt extract Oxoid, per litre) after $14 \mathrm{~h}$ at $24 \pm 1{ }^{\circ} \mathrm{C}$ in darkness under shaking (120 rpm).

Table 1 Monilinia isolates and experimental conditions

\begin{tabular}{|c|c|c|c|c|c|}
\hline \multirow[t]{2}{*}{ Species } & \multirow[t]{2}{*}{ Isolate } & \multirow{2}{*}{$\begin{array}{l}\text { Mating } \\
\text { type }\end{array}$} & \multicolumn{2}{|l|}{ Origin } & \multirow{2}{*}{$\underset{¥}{\text { Sample ID }}$} \\
\hline & & & Host plant & Location & \\
\hline \multirow[t]{6}{*}{ Monilinia fructicola } & Mfrc123 & MAT1-1 & Cherry & Puglia & Mfrc123 D \\
\hline & & & & & Mfrc123 L \\
\hline & & & & & Mfrc123 C \\
\hline & Mfrc78 & MAT1-2 & Cherry & Campania & Mfrc78 D \\
\hline & & & & & Mfrc78 L \\
\hline & & & & & Mfrc78 C \\
\hline \multirow[t]{6}{*}{ Monilinia laxa } & Mlax316 & MAT1-1 & Cherry & Puglia & Mlax316 D \\
\hline & & & & & Mlax316 L \\
\hline & & & & & Mlax316 C \\
\hline & Mlax297 & MAT1-2 & Cherry & Puglia & Mlax297 D \\
\hline & & & & & Mlax297 L \\
\hline & & & & & Mlax297 C \\
\hline \multirow[t]{6}{*}{ Monilinia fructigena } & Mfrg269 & MAT1-1 & Plum & Basilicata & Mfrg269 D \\
\hline & & & & & Mfrg269 L \\
\hline & & & & & Mfrg269 C \\
\hline & Mfrg344 & MAT1-2 & Pear & Emilia-Romagna & Mfrg344 D \\
\hline & & & & & Mfrg344 L \\
\hline & & & & & Mfrg344 C \\
\hline
\end{tabular}


RNA extraction, library preparation and sequencing

Total RNA was extracted from a total of 18 samples $(6$ per species) made up by $100 \mathrm{mg}$ of mycelium or germinated conidia with the RNeasy Plant Mini Kit (Qiagen, Milan, Italy), following the manufacturer's protocol. cDNA libraries were prepared from $4 \mu \mathrm{g}$ of total RNA using the TruSeq RNA Sample Preparation Kit v2 (Illumina, Inc., San Diego, CA, USA) and validated according to Illumina's low-throughput protocol. The protocol was adjusted to obtain an average library size of about $400 \mathrm{bp}$ (insert length $130-290 \mathrm{bp}$ ), by reducing RNA fragmentation time to 2 min at $94{ }^{\circ} \mathrm{C}$. Sequencing was carried out on an Illumina HiScanSQ platform using TruSeq SBS kit v3 (Illumina, Inc.) to obtain paired-end reads, $92 \mathrm{nt}$ in length. RNA and DNA quantity and quality were determined with a Nanodrop 2000 spectrophotometer (Thermo Fisher Scientific Inc., Wilmington, DE, USA) and a Bioanalyzer 2100 (Agilent Technologies, Santa Clara, CA, USA). After removing indexed adapters, reads from each library were filtered for quality score $(\mathrm{QS} \geq 30)$ using CASAVA v1.8 software (Illumina, Inc.).

\section{Sequencing read quality and trimming}

Reads were analysed for quality statistics, nucleotide distribution and redundancy using FastX-tools (http:// hannonlab.cshl.edu/fastx_toolkit), and trimmed with Trimmomatic $0.36 \quad$ (http://www.usadellab.org/cms/ index.php?page=trimmomatic) setting the parameters as follows: i) LEADING and TRAILING $=3$, removing bases from the two ends of the reads if below a threshold quality of 3; ii) SLIDING WINDOW $=4: 2$, cutting the reads when the average quality within the window composed of 4 bases falls below a threshold equal to 2; iii) $\operatorname{MINLEN~}=50$, removing the reads shorter than $50 \mathrm{bp}$ [15].

\section{Transcriptome de novo assembly}

Trinity software v.2.1.1 (https://github.com/trinityrnaseq/ trinityrnaseq/wiki) was used for the de novo assembly of the transcriptomes using together sequencing data from the six libraries ( 2 isolates and 3 growing conditions) from each species (Table 1). Default assembly parameters of Trinity were used, with the addition of the "-jaccard_clip" function because a high gene density with overlapping of UnTranslated Region (UTR) was expected [16].

\section{Functional annotation}

The annotation of the putative transcripts obtained from each assembly was performed using local BLAST + 2.3.0 (ftp://ftp.ncbi.nlm.nih.gov/blast/executables/blast+/) [17] and Blast2GO PRO v4.0.7 [18]. BLASTx analysis was carried out by searching against the NCBI non-redundant protein database (downloaded 22 November 2016) and setting E-value cut off at $10^{-3}$. Blast2GO PRO was used to predict Gene Ontology
(GO) terms, to assign the assembled sequences to the Kyoto Encyclopedia of Genes and Genomes (KEGG) pathways, and to analyse protein domains using the InterProScan tool. Blast2GO annotation search was conducted with $10^{-6}$ as the E-value hit filter, 55 as the annotation cut-off and 5 as the GO weight; no HSP-hit coverage cut-off was considered. Moreover, all GO terms retrieved via InterProScan analysis were added and used to validate $\mathrm{GO}$ annotations; further enhancement of GO terms was conducted with Annotation Expander (ANNEX).

\section{Transcriptome quality assessment}

For the first quality assessment, trimmed reads were realigned on the assembled transcriptomes using CLC Genomics Workbench v.7.0.3 (CLC bio, Aarhus, Denmark), setting the parameters as follows: i) mismatch cost $=2$; ii) insertion cost $=3$; iii) deletion cost $=3$; iv) length fraction $=0.8 ; \mathrm{v}$ ) similarity fraction $=0.8$.

The Trinity script analyze_blastPlus_topHit_coverage.pl (https://github.com/trinityrnaseq/trinityrnaseq/wiki/Counting-Full-Length-Trinity-Transcripts) was launched to determine the number of full-length or nearly full-length transcripts using BLAST+ with an E-value cut off $10^{-20}$ and a protein database built from the proteome of B. cinerea (ASM83294v1; http://fungi.ensembl.org/Botrytis_cinerea/Info/Index, downloaded 10 April 2016), used as the closest related organism.

Putative Open Reading Frames (ORFs) within transcript sequences were predicted with TransDecoder v2.1 (http:// transdecoder.github.io) and transcriptome completeness was assessed using BUSCO v1.2 (Benchmarking Universal Single-Copy Orthologs; http://busco.ezlab.org) [19] on the ground of 1438 conserved fungal orthologs (downloaded 21 October 2016).

\section{Comparative transcriptome analysis}

tBLASTn search was used to identify orthologous transcripts in the three Monilinia species. In detail, Botrytis cinerea B05.10 proteins (ASM83294v1) integrated with the mitochondrial proteins (ftp://ftp.broadinstitute.org/ pub/annotation/fungi/botrytis_cinerea/genomes/botrytis_cinerea_b05.10_mito, downloaded 10 April 2016) were queried against the assembled transcriptomes of MFRC, MLAX and MFRG, to identify homologous sequences. tBLASTn was run using CLC Genomics Workbench with a threshold E-value $<10^{-3}$. Reads were then mapped on the selected transcripts and the unmapped reads re-aligned on the complete Trinity transcriptomes, to retrieve Monilinia transcripts with not homologs in the $B$. cinerea proteome; all transcripts with counted reads $>50$ and significant matches to fungal proteins in BLASTx search were 
included for further analysis. Homology between the putative Monilinia orthologs was assessed through BLASTn pairwise alignments in all possible combinations (MFRC vs MLAX; MFRC vs MFRG; and MFRG vs MLAX) with the threshold parameter of E-value< $10^{-10}$

Reads from each isolate per species were mapped on the identified set of orthologous transcripts using CLC Genomics Workbench with the previously reported alignment parameter setting. The values of gene expression were measured in reads per $\mathrm{Kb}$ of transcript per million mapped reads (RPKM). The data from the three growing conditions for each isolate were pooled and used as two biological replicates per each species. Fold Change (FC) was calculated comparing the RPKM values in all pairwise combinations between the three fungal species. False Discovery Rate (FDR) was determined using the edgeR Bioconductor package [20] and transcripts with $\mathrm{FC}>|8|$ and $\mathrm{FDR} \leq 0.05$ in both the comparisons of each species with the other two were considered as differentially expressed transcripts (DETs) and submitted to functional analysis. For an accurate comparison among the species, we removed from the identified DET sets: i) incorrectly associated transcripts revealed by pairwise BLASTn alignments, including those with doubtful RPKM values due to multiple isoforms; and ii) chimeric transcripts identified by BLASTx, i.e. assembled sequences derived from two or more adjacent transcribed genes [21].

WEGO was used to perform functional classification of Trinity unigenes based on the GO annotation and compare the overall distribution of gene functions in the three species using the Pearson Chi-Square test [22]. All unigenes from each transcriptome were also submitted to search against the EggNog (Evolutionary genealogy of genes: Non-supervised Orthologous Groups) database, integrated in the Blast2GO pipeline, to predict and classify gene functions based on sequence similarity within clusters of orthologous groups (OGs) [23].

\section{Results}

Sequencing and transcriptome de novo assembly

Illumina mRNA sequencing from germinating conidia and actively growing mycelia of two isolates of opposite mating type per each species generated a total of $19.5 \mathrm{~Gb}$, more than $6 \mathrm{~Gb}$ per species corresponding to about 70 million of paired-end reads (Additional file 1: Table S1).

After trimming of low quality reads, less than $1 \%$ of input paired-end reads were discarded, and the remaining reads used for de novo assembly. The most relevant data are in Table 2. Overall, Trinity assembly generated 33,861 contigs for MFRC, 31,103 for MLAX and 28,890 for MFRG corresponding to putative transcripts, including isoforms. The number of unigenes assembled by Trinity exceeded the expected number of protein coding genes, likely due to fragmented transcripts, i.e. unigenes representing the same transcript that could not be assembled because containing a gap.

\section{Quality assessment of de novo assembly}

More than $80 \%$ of the paired-end reads used for the assembly successfully mapped to the respective assembled transcriptome used as reference (Additional file 1: Table S2).

About 8000 transcripts of each transcriptome showed homology with B. cinerea. Most of them (84\% for MFRC, $83 \%$ for MLAX, $79 \%$ for MFRG) displayed a coverage higher than $70 \%$ of the protein length. TransDecoder identified 23,738, 18,756 and 16,823 candidate ORFs in the MFRC, MLAX and MFRG transcriptomes and $76.4,72.7$ and $65.5 \%$, in the order, were complete.

Data obtained from transcriptome completeness analysis by BUSCO, based only on conserved fungal orthologs, showed that over $90 \%$ of the assembled transcripts for the three Monilinia species were complete and that the percentage of duplicated transcripts was always less than $14 \%$. Less than $10 \%$ of transcripts were fragmented or missing (Table 3).

Table 2 Statistics of Trinity assembly

\begin{tabular}{llll}
\hline & Monilinia fructicola & Monilinia laxa & Monilinia fructigena \\
\hline Number of transcripts & 33,861 & 31,103 & 28,890 \\
Number of unigenes & 27,692 & 27,334 & 25,781 \\
Average transcript length (bp) & 1545 & 1334 & 1199 \\
Transcript N50 & 2799 & 2397 & 2189 \\
Maximum length (bp) & 13,605 & 15,609 & 15,798 \\
Total assembled bases (Mb) & 52.3 & 41.6 & 34.6 \\
GC content (\%) & 45 & 44 & 44 \\
\hline
\end{tabular}


Table 3 Results of BUSCO analysis on the assembled transcriptomes

\begin{tabular}{|c|c|c|c|c|c|}
\hline \multirow[t]{3}{*}{ Species } & \multicolumn{5}{|c|}{ Orthologs $\left(\mathrm{N}^{\circ}\right)^{*}$} \\
\hline & \multicolumn{3}{|l|}{ Complete } & \multirow[t]{2}{*}{ Fragmented } & \multirow[t]{2}{*}{ Missing } \\
\hline & Total & Single-copy & Duplicated & & \\
\hline Monilinia fructicola & 1317 (91\%) & $1110(77 \%)$ & 207 (14\%) & $51(4 \%)$ & $70(5 \%)$ \\
\hline Monilinia laxa & $1327(92 \%)$ & $1167(81 \%)$ & $160(11 \%)$ & $40(3 \%)$ & $71(5 \%)$ \\
\hline Monilinia fructigena & 1303 (90\%) & 1146 (80\%) & 157 (10\%) & $67(5 \%)$ & $68(5 \%)$ \\
\hline
\end{tabular}

₹ Percentages refer to the BUSCO dataset including 1438 conserved fungal orthologs (http://busco.ezlab.org/v1)

\section{Functional annotation}

More than $50 \%$ of the assembled contigs had a significant hit in BLASTx search (Table 4). The top-hits by species distribution analysis showed the highest similarities with B. cinerea (strains BcDW1, T4 or B05.10), Sclerotinia sclerotiorum (1980 UF-70) and Sclerotinia borealis (F-4157) (Fig. 1a). The E-value distribution of the top blast hits showed about $50 \%$ of hits with an E-value equal to zero and about $70 \%$ with E-values ranging from 0 to $1 \mathrm{e}-61$ (Fig. 1c). Sequences with no significant hits were mostly short fragments (Fig. 1b) or non-coding RNA sequences. The GO search assigned 18,839 GO terms, including the three main categories of biological process, molecular function and cellular component, to 13,538 contigs in MFRC, 16,462 GO terms to 12,082 contigs in MLAX, and $16,776 \mathrm{GO}$ terms to 12,238 contigs in MFRG.

In the three transcriptomes, more than $80 \%$ of the unigenes with a significant hit were associated to at least one GO term, and the GO terms were functionally classified and plotted. The three transcriptomes were very similar in their profiles of unigene distribution in functional categories (Fig. 2). Many unigenes were assigned to cellular and metabolic processes and to biological processes related to morphogenesis, localization, pigmentation, development and growth, reproduction, response to stimulus, multi-organism and multicellular organismal processes. In the molecular function category, binding and catalytic activities represented the majority followed by transporters, structural molecules and enzymes, transcription and translation regulation. In the cellular component category, cell, cell part, organelle and macromolecular complex were prevalently represented.

In addition, BLAST and GO mapping results were used to assign unigenes to clusters of OGs using the EggNog database. In total 2536 (MFRC), 2734 (MLAX) and 2753 (MFRG) unigenes (17-23\% of the genes with BLAST hits) were assigned to 24 functional categories of clusters of OGs (Fig. 3). The largest group was represented by the cluster of unigenes with "function unknown" (37-43\%), followed by "secondary metabolites biosynthesis, transport and catabolism" (14-17\%), "carbohydrate transport and metabolism" (14-15\%), "translation, ribosomal structure and biogenesis" (11-15\%), "posttranslational modification, protein turnover, chaperones" (12-13\%), "lipid transport and metabolism" (11\%), "energy production and conversion" (9-11\%), "signal transduction mechanisms" (9-11\%), "amino acid transport and metabolism" (10\%). Clusters such as "cell motility", "extracellular structures" and "nuclear structure" were poorly represented $(<0.1 \%)$ or absent. The number of unigenes enclosed in the OG clusters "function unknown" in MFRG and "translation, ribosomal structure and biogenesis" in MLAX were higher as compared to the other two species.

\section{Comparative transcriptome analysis}

Ten-thousand four-hundred and fifty-two putative orthologous transcripts were identified among the three Monilinia species. In detail, 10,045 orthologs were identified by tBLASTn analysis using the proteome of $B$. cinerea as reference, whereas 407 transcripts were specific for at least one of the Monilinia species and had not homologous sequences in $B$. cinerea proteins.

Differential expression analysis of orthologs was carried out by comparing RPKM values in each species versus the other two. We identified 301 exclusive or over-expressed orthologs $(\mathrm{FC} \geq 8$; FDR $\leq 0.05)$ in MFRC, 159 in MLAX and 215 in MFRG (Fig. 4). Transcripts with uninformative BLAST hits ( 45\%, for MFRC and

Table 4 Results of functional analysis of transcriptomes

\begin{tabular}{llll}
\hline Numbers & Monilinia fructicola & Monilinia laxa & Monilinia fructigena \\
\hline Total transcripts & 33,861 & 31,103 & 28,890 \\
No Blast Hits & 15,382 & 14,304 & 12,243 \\
With Blast Hits & 2902 & 2928 & 2670 \\
With Mapping & 2055 & 1814 & 1580 \\
With GO Annotation & 13,522 & 12,057 & 12,397 \\
Transcripts with significant hit (\%) & 54.5 & 54.0 & 57.6 \\
\hline
\end{tabular}




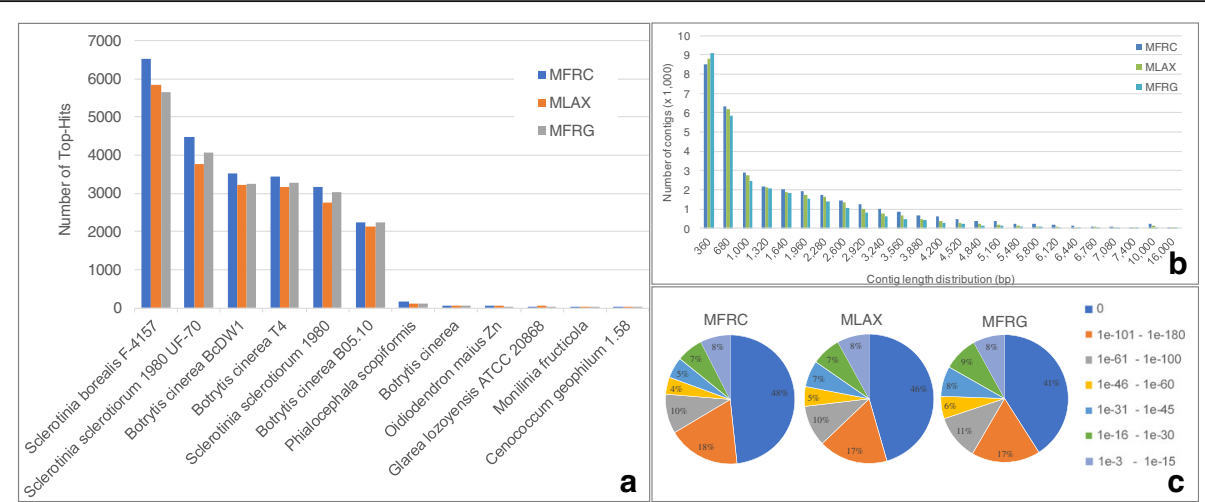

Fig. 1 Top-hit species (a), contig length (b) and E-value (c) distributions in the transcriptomes of Monilinia fructicola (MFRC), Monilinia laxa (MLAX) and Monilinia fructigena (MFRG)

MLAX, and $22 \%$ for MFRG) were discharged. Finally, we identified 65 DETs significantly over-expressed or exclusive for MFRC, 30 in MLAX and 31 in MFRG, that were categorized into nine major functional groups: 1) hydrolytic and carbohydrate-active enzymes, 2) effector and secreted proteins; 3) morphogenesis and development; 4) regulation and signalling; 5) membrane proteins and transport; 6) secondary metabolite biosynthesis; 7) oxidation-reduction processes; 8) nucleic acid modification and metabolism; and 9) miscellaneous (Table 5). Heat-map representation of expression profiles of the DETs from the two isolates per species under the different growing conditions confirmed the diversity among the species revealed by mapping pooled reads of each isolate and showed differences between germinating conidia and mycelium samples that are not analysed in the present paper (Fig. 5).

\section{Hydrolytic and carbohydrate-active enzymes}

Twelve DETs encoding hydrolytic or carbohydrate-active enzymes were over-expressed in MFRC, including glycoside hydrolases (GHs) such as a $\beta$-1,3-glucan binding protein of the GH16 family (T9687; FC $=11.4-16.2$ ); two DETs (T9618 and T10205; FC $\geq 10$ ), only partially reconstructed in MLAX and MFRG, encode respectively an $\alpha$-L-arabinofuranosidase (GH51) and a chitin-binding

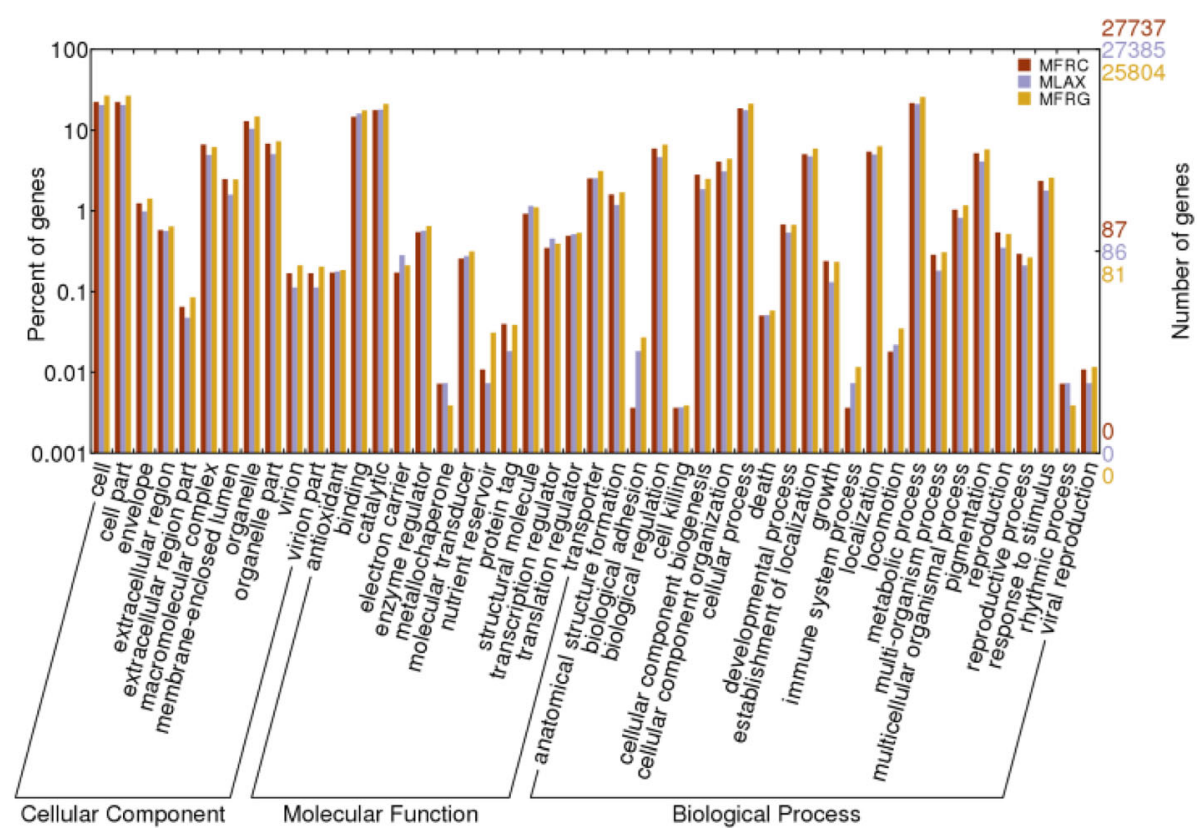

Fig. 2 Frequency distribution of Gene Ontology (GO) terms grouped into the main functional categories of cellular component, molecular function and biological process. The right $y$-axis indicates the number of unigenes per category. The left y-axis indicates the percentage of a specific category of unigenes in the main category 


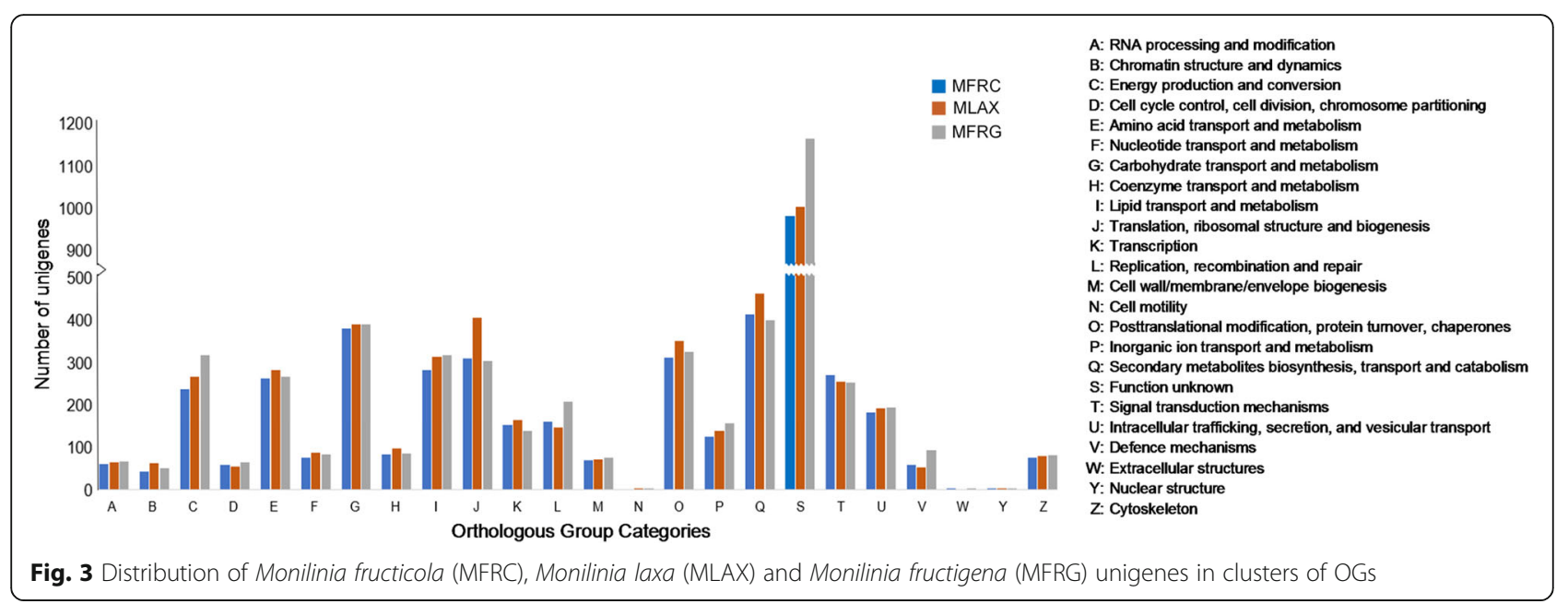

type 1 protein (GH18) with a homolog in Macrophomina phaseolina (E-value $=4 \mathrm{e}-63 ; \mathrm{id}=58 \%$; and the partial sequence (T10086) of a putative GH65 family protein assembled only in MFRC. Full-length or partial DETs annotated as $\alpha / \beta$ hydrolases were over-expressed (T9625, T9489 and T9732) or uniquely assembled (T10098) in MFRC. The protein encoded by T9489 (FC =8.3, with no homologs in MFRG) contains conserved domains and exhibits some sequence similarity (E-value $\geq 4 \mathrm{e}-35$; id $=33 \%$ ) to carboxylesterases and lipases from fungi, but not in Botrytis and Sclerotinia spp.. A galactose oxidase precursor protein (T9679; FC $=12.2-15.8)$ and a pectate lyase (T9581; FC $=10.4-13.4$ ) were also detected. T10089, with no orthologs in MLAX and MFRG, showed similarities to a hypothetical protein of S. sclerotiorum and to amidohydrolase 2 of $M$. phaseolina $(\mathrm{E}$-value $=4 \mathrm{e}-07$; id $=46 \%)$ and other fungi, but not B. cinerea.

Nine DETs of the same enzymatic group were over-expressed in MLAX including a putative ß-1,6-galactanase protein (T309; FC = 9.7-19.4), member of GH5 family. Two additional GHs $(\mathrm{FC}=8.0-11.8)$ were a putative xyloglucan-specific endo- $\beta-1,4$-glucanase (GH12; T288) and an $\alpha-1,2-$ mannosidase (GH92; T310). A fungal phospholipase B-like domain was identified in T163 (FC $=8.5-20.2) . \alpha / \beta$ hydrolases included a prolyl aminopeptidase (T181; $\mathrm{FC}=16.3-18.3$ ), as well as two additional DETs $(\mathrm{FC}=10.3-64.1)$ encoding a pectin methylesterase (T99) and laccase 2 (T53). Finally, the hydroxyacylglutathione hydrolase T96 ( FC = 30.7-32.8) and a putative extracellular intradiol dioxygenase (T240; $\mathrm{FC}=8.6-12.5)$ were among DETs identified in MLAX.

Four DETs were over-expressed in MFRG, including T7115 ( $\mathrm{FC}=9.0-12.8)$ encoding a putative $\alpha$-amylase (GH13 family), and T6223 ( $\mathrm{FC}=18.8-22.1)$ encoding a ß-mannosidase B-like protein ( $\mathrm{GH} 2$ family). Moreover, we detected a carbohydrate esterase family 12 protein (T8110; FC = 12.3-24.9), involved in degradation of pectin in cell wall, and a cellobiose dehydrogenase $(\mathrm{CDH})$ (T9172; FC = 9.2-43.8), involved in cellulose degradation, having homologs (E-value $=0$; id $\geq 79 \%)$ in $S$. borealis and S. sclerotiorum but not in B. cinerea.

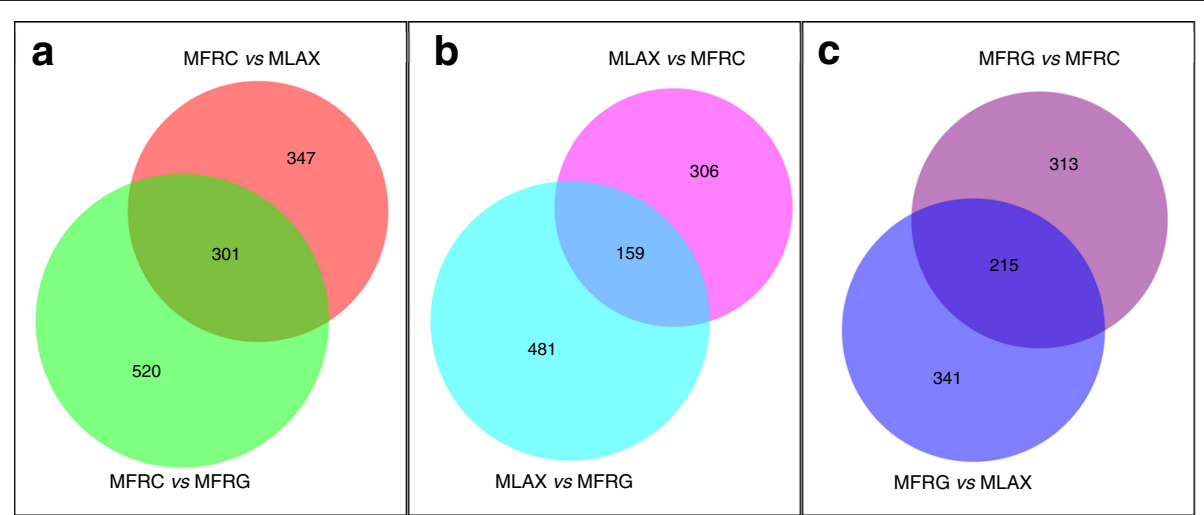

Fig. 4 Venn diagrams of transcripts exclusive for or over-expressed (FC $\geq 8 ; F D R \leq 0.05$ ) in Monilinia fructicola (MFRC; a), Monilinia laxa (MLAX; b) and Monilinia fructigena (MFRG; $\mathbf{c}$ ) as compared to the other two species 
Table 5 Differentially expressed transcripts (DETs) identified in Monilinia fructicola (MFRC), Monilinia laxa (MLAX) and Monilinia fructigena (MFRG)

\begin{tabular}{|c|c|c|c|c|c|c|c|c|c|}
\hline \multirow{3}{*}{$\begin{array}{l}\text { Transcript } \\
\text { ID }\end{array}$} & \multirow{3}{*}{$\begin{array}{l}\text { Botrytis cinerea } \\
\text { protein ID }\end{array}$} & \multicolumn{2}{|l|}{ MFRC } & \multicolumn{2}{|l|}{ MLAX } & \multicolumn{2}{|l|}{ MFRG } & Expression values & \multirow{3}{*}{$\begin{array}{l}\text { Putative protein function } \\
\text { (BLASTx) }\end{array}$} \\
\hline & & \multirow{2}{*}{$\begin{array}{l}\text { Contig } \\
\text { size (bp) }\end{array}$} & \multirow{2}{*}{$\begin{array}{l}\text { E-value } \\
\text { (tBLASTn) }\end{array}$} & \multirow{2}{*}{$\begin{array}{l}\text { Contig } \\
\text { size (bp) }\end{array}$} & \multirow{2}{*}{$\begin{array}{l}\text { E-value } \\
\text { (tBLASTn) }\end{array}$} & \multirow{2}{*}{$\begin{array}{l}\text { Contig } \\
\text { size } \\
\text { (bp) }\end{array}$} & \multirow{2}{*}{$\begin{array}{l}\text { E-value } \\
\text { (tBLASTn) }\end{array}$} & (RPKM) & \\
\hline & & & & & & & & $\overline{\text { MFRC } \quad \text { MLAX } \quad \text { MFRG }}$ & \\
\hline
\end{tabular}

Hydrolytic and carbohydrate-active enzymes

\begin{tabular}{|c|c|c|c|c|c|c|c|c|c|c|c|}
\hline T9687 & Bcin12g01530.1 & 2023 & $0.0 \mathrm{E}+00$ & 2275 & $0.0 \mathrm{E}+00$ & 2093 & $0.0 \mathrm{E}+00$ & 209.2 & 12.9 & 18.3 & $\begin{array}{l}\text { glycoside hydrolase family } 16 \\
\text { protein }\end{array}$ \\
\hline T9618 & Bcin09g04440.1 & 2342 & $0.0 \mathrm{E}+00$ & 1399 & $0.0 \mathrm{E}+00$ & 247 & $8.0 \mathrm{E}-43$ & 45.8 & 3.7 & 0.4 & $\begin{array}{l}\text { glycoside hydrolase family } 51 \\
\text { protein }\end{array}$ \\
\hline T10205 & Bcin03g01930.1 & 3806 & $6.4 \mathrm{E}-15$ & 233 & - & 619 & $1.4 \mathrm{E}-30$ & 9.9 & 0.3 & 1.0 & $\begin{array}{l}\text { glycoside hydrolase family } 18 \\
\text { protein }\end{array}$ \\
\hline T10086 & $\mathrm{NH}$ & 745 & - & - & - & - & - & 12.9 & - & - & $\begin{array}{l}\text { glycoside hydrolase family } 65 \\
\text { protein }\end{array}$ \\
\hline T309 & Bcin07g02650.1 & 1555 & $0.0 \mathrm{E}+00$ & 1443 & $0.0 \mathrm{E}+00$ & 579 & $9.9 \mathrm{E}-102$ & 2.4 & 23.3 & 1.2 & $\begin{array}{l}\text { glycoside hydrolase family } 5 \\
\text { protein }\end{array}$ \\
\hline T288 & Bcin13g02320.1 & 1628 & $1.4 \mathrm{E}-118$ & 1166 & $1.2 \mathrm{E}-120$ & 1306 & $4.5 \mathrm{E}-120$ & 9.1 & 95.8 & 11.5 & $\begin{array}{l}\text { glycoside hydrolase family } 12 \\
\text { protein }\end{array}$ \\
\hline Т310 & Bcin06g00580.1 & 3397 & $0.0 \mathrm{E}+00$ & 2763 & $0.0 \mathrm{E}+00$ & 1871 & $0.0 \mathrm{E}+00$ & 3.4 & 40.2 & 5.0 & $\begin{array}{l}\text { glycoside hydrolase family } 92 \\
\text { protein }\end{array}$ \\
\hline T6223 & Bcin05g01040.1 & 3259 & $0.0 \mathrm{E}+00$ & 3361 & $0.0 \mathrm{E}+00$ & 3461 & $0.0 \mathrm{E}+00$ & 7.3 & 6.2 & 137.4 & $\begin{array}{l}\text { glycoside hydrolase family } 2 \\
\text { protein }\end{array}$ \\
\hline T7115 & Bcin02g01420.1 & 1898 & $0.0 \mathrm{E}+00$ & 1148 & 9.7E-175 & 1966 & $0.0 \mathrm{E}+00$ & 5.1 & 3.6 & 46.0 & $\begin{array}{l}\text { glycoside hydrolase family } 13 \\
\text { protein }\end{array}$ \\
\hline T9625 & Bcin02g05500.1 & 1569 & $0.0 \mathrm{E}+00$ & 1814 & $0.0 \mathrm{E}+00$ & 221 & 1.7E-09 & 56.7 & 4.4 & 0.5 & $\alpha / \beta$ hydrolase \\
\hline T9489 & $\mathrm{NH}$ & 2787 & - & 1261 & - & - & - & 15.0 & 1.8 & - & $\alpha / \beta$ hydrolase \\
\hline T9732 & $\mathrm{NH}$ & 535 & - & 531 & - & 361 & - & 29.0 & 1.5 & 0.6 & $\alpha / \beta$ hydrolase, partial \\
\hline T10098 & $\mathrm{NH}$ & 1969 & - & - & - & - & - & 3.0 & - & - & putative $\alpha / \beta$ hydrolase \\
\hline T10089 & $\mathrm{NH}$ & 2310 & - & - & - & - & - & 2.3 & - & - & putative amidohydrolase 2 \\
\hline T9679 & Bcin13g05710.1 & 4801 & $0.0 \mathrm{E}+00$ & 4584 & $0.0 \mathrm{E}+00$ & 3012 & $0.0 \mathrm{E}+00$ & 113.9 & 7.2 & 9.3 & $\begin{array}{l}\text { galactose oxidase precursor } \\
\text { protein }\end{array}$ \\
\hline T9581 & Bcin10g05620.1 & 1278 & $2.3 \mathrm{E}-100$ & 1211 & $6.7 \mathrm{E}-100$ & 1225 & $1.4 \mathrm{E}-101$ & 32.1 & 3.1 & 2.4 & pectate lyase \\
\hline T9586 & Bcin14g00570.1 & 903 & $2.8 \mathrm{E}-61$ & - & - & - & - & 17.9 & - & - & serine hydrolase FSH \\
\hline T53 & Bcin01g07950.1 & 2112 & $0.0 \mathrm{E}+00$ & 2475 & $0.0 \mathrm{E}+00$ & 2303 & $0.0 \mathrm{E}+00$ & 3.1 & 198.8 & 11.8 & laccase 2 \\
\hline T99 & Bcin03g03830.1 & 1683 & $6.8 \mathrm{E}-179$ & 1640 & $1.9 \mathrm{E}-177$ & 1352 & $0.0 \mathrm{E}+00$ & 7.4 & 245.0 & 23.9 & pectin methylesterase \\
\hline Т163 & Bcin01g02320.1 & 3743 & $0.0 \mathrm{E}+00$ & 4284 & $0.0 \mathrm{E}+00$ & 2008 & $0.0 \mathrm{E}+00$ & 11.3 & 228.3 & 26.8 & lysophospholipase \\
\hline T181 & Bcin12g04910.1 & 7278 & 1.3E-108 & 1847 & 2.6E-113 & 1546 & 6.7E-101 & 4.1 & 74.9 & 4.6 & prolyl aminopeptidase \\
\hline T96 & Bcin03g05490.1 & 1965 & $3.2 \mathrm{E}-175$ & 1229 & 1.3E-176 & 1544 & 5.7E-174 & 2.9 & 95.1 & 3.1 & $\begin{array}{l}\text { hydroxyacylglutathione } \\
\text { hydrolase }\end{array}$ \\
\hline T240 & Bcin02g00018.1 & 1916 & $2.5 \mathrm{E}-93$ & 1436 & 4.2E-94 & 1694 & $1.1 \mathrm{E}-95$ & 3.1 & 38.6 & 4.5 & extracellular dioxygenase \\
\hline T9172 & $\mathrm{NH}$ & 3183 & - & 1985 & - & 3442 & - & 6.7 & 1.4 & 61.3 & cellobiose dehydrogenase \\
\hline T8110 & Bcin02g07100.1 & 3717 & 1.7E-144 & 1579 & 5.5E-151 & 1028 & $2.2 \mathrm{E}-152$ & 9.1 & 4.5 & 112.2 & $\begin{array}{l}\text { carbohydrate esterase family } \\
12 \text { protein }\end{array}$ \\
\hline \multicolumn{12}{|c|}{ ffector and secreted proteins } \\
\hline T9637 & Bcin05g01800.1 & 1507 & 3.7E-87 & 1157 & $6.0 \mathrm{E}-71$ & 1101 & $7.2 \mathrm{E}-73$ & 74.7 & 5.8 & 1.9 & protease inhibitor \\
\hline T9520 & Bcin14g04460.1 & 5479 & $0.0 \mathrm{E}+00$ & 5131 & $0.0 \mathrm{E}+00$ & 2153 & $0.0 \mathrm{E}+00$ & 104.0 & 11.6 & 9.2 & RHS repeat protein \\
\hline T9914 & Bcin11g02900.1 & 1018 & $3.6 \mathrm{E}-158$ & 365 & $8.9 \mathrm{E}-65$ & 997 & $6.0 \mathrm{E}-91$ & 20.2 & 0.1 & 2.0 & trypsin-like serine protease \\
\hline T144 & Bcin03g03300.1 & 2948 & $5.4 \mathrm{E}-98$ & 1189 & $1.5 \mathrm{E}-126$ & 2152 & 7.7E-69 & 6.5 & 144.7 & 9.3 & pepsin (secreted protein) \\
\hline \multicolumn{12}{|c|}{ Aorphogenesis and development } \\
\hline T9903 & $\mathrm{NH}$ & 1255 & - & 1904 & - & 1965 & - & 593.7 & 4.0 & 18.1 & $\begin{array}{l}\text { developmental-specific } \\
\text { protein Ssp1 }\end{array}$ \\
\hline
\end{tabular}


Table 5 Differentially expressed transcripts (DETs) identified in Monilinia fructicola (MFRC), Monilinia laxa (MLAX) and Monilinia fructigena (MFRG) (Continued)

\begin{tabular}{|c|c|c|c|c|c|c|c|c|c|c|c|}
\hline \multirow{3}{*}{$\begin{array}{l}\text { Transcript } \\
\text { ID }\end{array}$} & \multirow{3}{*}{$\begin{array}{l}\text { Botrytis cinerea } \\
\text { protein ID }\end{array}$} & \multicolumn{2}{|l|}{ MFRC } & \multicolumn{2}{|l|}{ MLAX } & \multicolumn{2}{|l|}{ MFRG } & \multirow{2}{*}{\multicolumn{3}{|c|}{$\frac{\text { Expression values }}{\text { (RPKM) }}$}} & \multirow{3}{*}{$\begin{array}{l}\text { Putative protein function } \\
\text { (BLASTx) }\end{array}$} \\
\hline & & \multirow{2}{*}{$\begin{array}{l}\text { Contig } \\
\text { size (bp) }\end{array}$} & \multirow{2}{*}{$\begin{array}{l}\text { E-value } \\
\text { (tBLASTn) }\end{array}$} & \multirow{2}{*}{$\begin{array}{l}\text { Contig } \\
\text { size (bp) }\end{array}$} & \multirow{2}{*}{$\begin{array}{l}\text { E-value } \\
\text { (tBLASTn) }\end{array}$} & \multirow{2}{*}{$\begin{array}{l}\text { Contig } \\
\text { size } \\
\text { (bp) }\end{array}$} & \multirow{2}{*}{$\begin{array}{l}\text { E-value } \\
\text { (tBLASTn) }\end{array}$} & & & & \\
\hline & & & & & & & & MFRC & MLAX & MFRG & \\
\hline T9722 & Bcin15g04790.1 & 1315 & $2.2 \mathrm{E}-177$ & 1359 & 4.5E-176 & 1303 & $2.4 \mathrm{E}-180$ & 315.4 & 16.5 & 31.1 & elongation of fatty acid protein \\
\hline T9697 & Bcin08g05540.1 & 1612 & $2.6 \mathrm{E}-124$ & 2603 & $2.7 \mathrm{E}-120$ & 1525 & $3.4 \mathrm{E}-123$ & 89.4 & 5.6 & 4.5 & $\begin{array}{l}\text { gas1-like protein/cell surface } \\
\text { protein }\end{array}$ \\
\hline T9572 & Bcin14g04260.1 & 4771 & $2.8 \mathrm{E}-157$ & 2666 & $3.4 \mathrm{E}-163$ & 1333 & $1.5 \mathrm{E}-165$ & 70.1 & 7.0 & 7.6 & $\begin{array}{l}\text { cell surface protein/related to } \\
\text { gEgh } 16 \text { protein }\end{array}$ \\
\hline T9843 & Bcin15g03000.1 & 1843 & $4.2 E-53$ & 1782 & $8.1 \mathrm{E}-46$ & 2404 & $1.1 \mathrm{E}-56$ & 186.9 & 3.2 & 11.8 & putative cell wall protein SED1 \\
\hline T9480 & Bcin02g03060.1 & 3163 & $0.0 \mathrm{E}+00$ & 3630 & $0.0 \mathrm{E}+00$ & 1999 & $0.0 \mathrm{E}+00$ & 85.8 & 10.6 & 5.9 & fatty acid oxygenase protein \\
\hline T205 & Bcin12g05860.1 & 1706 & $3.6 \mathrm{E}-159$ & 1271 & $2.4 \mathrm{E}-158$ & 1141 & 3.1E-157 & 7.5 & 114.0 & 3.4 & gpi anchored protein \\
\hline \multicolumn{12}{|c|}{ Regulation and signalling } \\
\hline T9760 & Bcin12g01420.1 & 2515 & $0.0 \mathrm{E}+00$ & 2372 & $0.0 \mathrm{E}+00$ & 1730 & $0.0 \mathrm{E}+00$ & 38.5 & 1.8 & 4.7 & $\begin{array}{l}\text { transcription factor cys } 6 \\
\text { protein }\end{array}$ \\
\hline T9765 & $\mathrm{NH}$ & 469 & - & 836 & - & 336 & - & 16.3 & 0.4 & 1.7 & c6 transcription factor \\
\hline T10202 & Bcin12g02660.1 & 1341 & $6.4 \mathrm{E}-115$ & - & - & 1058 & $2.7 E-108$ & 50.3 & - & 5.8 & $\begin{array}{l}\text { fungal specific transcription } \\
\text { factor protein }\end{array}$ \\
\hline T63 & Bcin05g06170.1 & - & - & 2572 & $1.2 \mathrm{E}-93$ & 1640 & 4.6E-93 & - & 4.0 & 46.6 & transcription factor $\mathrm{c} 2 \mathrm{~h} 2$ \\
\hline T9641 & $\mathrm{NH}$ & 1903 & - & 202 & - & - & - & 2.3 & 0.2 & - & camk protein kinase \\
\hline T9481 & Bcin05g04260.1 & 3343 & $0.0 \mathrm{E}+00$ & 670 & $1.7 \mathrm{E}-83$ & 218 & $2.0 \mathrm{E}-30$ & 6.9 & 0.8 & 0.3 & $\begin{array}{l}\text { serine threonine protein } \\
\text { kinase }\end{array}$ \\
\hline T321 & Bcin10g03050.1 & 1327 & $0.0 \mathrm{E}+00$ & 1586 & $0.0 \mathrm{E}+00$ & - & - & 4.6 & 43.5 & - & protein kinase-like protein \\
\hline T312 & Bcin14g02050.1 & 2114 & $0.0 \mathrm{E}+00$ & 1914 & $0.0 \mathrm{E}+00$ & 1770 & $0.0 \mathrm{E}+00$ & 7.0 & 64.5 & 4.9 & regulator of g protein \\
\hline T6048 & Bcin03g09060.1 & 909 & $6.6 \mathrm{E}-34$ & 560 & $1.4 \mathrm{E}-25$ & 1458 & $1.3 \mathrm{E}-25$ & 0.7 & 0.6 & 6.1 & $\begin{array}{l}\text { tetratricopeptide-like helical } \\
\text { protein }\end{array}$ \\
\hline T2642 & Bcin11g05000.1 & 670 & $3.5 \mathrm{E}-19$ & 512 & $1.6 \mathrm{E}-07$ & 1419 & 4.0E-49 & 0.7 & 1.2 & 131.2 & elongation factor 2 kinase \\
\hline T9894 & Bcin10g02660.1 & 1190 & $5.2 \mathrm{E}-143$ & 967 & 7.3E-146 & 5797 & $1.6 \mathrm{E}-130$ & 199.6 & 1.8 & 11.4 & MSS4-like protein \\
\hline \multicolumn{12}{|c|}{ Membrane proteins and transport } \\
\hline T10087 & $\mathrm{NH}$ & 1497 & - & - & - & - & - & 1.7 & - & - & $\begin{array}{l}\text { related to antibiotic resistance } \\
\text { protein }\end{array}$ \\
\hline T9642 & Bcin08g01830.1 & 1939 & $0.0 \mathrm{E}+00$ & 3904 & 2.0E-177 & 1626 & $0.0 \mathrm{E}+00$ & 178.8 & 13.0 & 13.2 & MFS transporter \\
\hline T9594 & Bcin09g01740.1 & 2209 & $0.0 \mathrm{E}+00$ & 2369 & $0.0 \mathrm{E}+00$ & 1175 & $0.0 \mathrm{E}+00$ & 18.7 & 1.6 & 1.5 & MFS drug efflux pump \\
\hline T9657 & Bcin12g01880.1 & 2434 & $0.0 \mathrm{E}+00$ & 577 & $1.9 \mathrm{E}-114$ & 949 & 4.1E-158 & 13.9 & 1.0 & 1.6 & MFS transporter \\
\hline T10002 & Bcin14g00580.1 & 2068 & $0.0 \mathrm{E}+00$ & - & - & - & - & 5.2 & - & - & $\begin{array}{l}\text { MFS multidrug transporter } \\
\text { protein }\end{array}$ \\
\hline T10106 & $\mathrm{NH}$ & 1913 & - & - & - & - & - & 1.0 & - & - & $\begin{array}{l}\text { MFS general substrate } \\
\text { transporter }\end{array}$ \\
\hline T9643 & Bcin06g00130.1 & 2760 & $0.0 \mathrm{E}+00$ & 3266 & $0.0 \mathrm{E}+00$ & 1839 & $0.0 \mathrm{E}+00$ & 114.9 & 8.5 & 4.9 & OPT oligopeptide transporter \\
\hline T9629 & Bcin10g00330.1 & 3305 & $0.0 \mathrm{E}+00$ & 1507 & $0.0 \mathrm{E}+00$ & 697 & $1.9 \mathrm{E}-144$ & 24.7 & 2.0 & 0.7 & potassium transporter protein \\
\hline T10105 & $\mathrm{NH}$ & 1321 & - & - & - & - & - & 11.7 & - & - & transmembrane protein \\
\hline T9893 & $\mathrm{NH}$ & 1461 & - & 450 & - & - & - & 84.0 & 0.7 & - & integral membrane protein \\
\hline T9288 & Bcin14g00590.1 & 1951 & $1.3 \mathrm{E}-117$ & - & - & - & - & 10.6 & - & - & $\begin{array}{l}\text { putative integral membrane } \\
\text { protein }\end{array}$ \\
\hline T9835 & Bcin12g05240.1 & 5309 & $0.0 \mathrm{E}+00$ & 508 & $8.5 \mathrm{E}-57$ & - & - & 8.7 & 0.2 & - & $\begin{array}{l}\text { Tat pathway signal sequence } \\
\text { protein }\end{array}$ \\
\hline T323 & Bcin03g01970.1 & 501 & 4.5E-07 & 2097 & $5.9 \mathrm{E}-09$ & - & - & 1.1 & 10.5 & - & $\begin{array}{l}\text { DUF3328 domain containing } \\
\text { protein }\end{array}$ \\
\hline
\end{tabular}


Table 5 Differentially expressed transcripts (DETs) identified in Monilinia fructicola (MFRC), Monilinia laxa (MLAX) and Monilinia fructigena (MFRG) (Continued)

\begin{tabular}{|c|c|c|c|c|c|c|c|c|c|c|c|}
\hline \multirow{3}{*}{$\begin{array}{l}\text { Transcript } \\
\text { ID }\end{array}$} & \multirow{3}{*}{$\begin{array}{l}\text { Botrytis cinerea } \\
\text { protein ID }\end{array}$} & \multicolumn{2}{|l|}{ MFRC } & \multicolumn{2}{|l|}{ MLAX } & \multicolumn{2}{|l|}{ MFRG } & \multirow{2}{*}{\multicolumn{3}{|c|}{$\frac{\text { Expression values }}{\text { (RPKM) }}$}} & \multirow{3}{*}{$\begin{array}{l}\text { Putative protein function } \\
\text { (BLASTx) }\end{array}$} \\
\hline & & \multirow{2}{*}{$\begin{array}{l}\text { Contig } \\
\text { size (bp) }\end{array}$} & \multirow{2}{*}{$\begin{array}{l}\text { E-value } \\
\text { (tBLASTn) }\end{array}$} & \multirow{2}{*}{$\begin{array}{l}\text { Contig } \\
\text { size (bp) }\end{array}$} & \multirow{2}{*}{$\begin{array}{l}\text { E-value } \\
\text { (tBLASTn) }\end{array}$} & \multirow{2}{*}{$\begin{array}{l}\text { Contig } \\
\text { size } \\
\text { (bp) }\end{array}$} & \multirow{2}{*}{$\begin{array}{l}\text { E-value } \\
\text { (tBLASTn) }\end{array}$} & & & & \\
\hline & & & & & & & & MFRC & MLAX & MFRG & \\
\hline T10081 & $\mathrm{NH}$ & 1907 & - & - & - & - & - & 1.9 & - & - & nrps-like enzyme protein \\
\hline T10004 & Bcin14g00600.1 & 5346 & $0.0 \mathrm{E}+00$ & - & - & - & - & 0.9 & - & - & polyketide synthase protein \\
\hline T8874 & Bcin12g04980.1 & 7211 & $0.0 \mathrm{E}+00$ & 2477 & $0.0 \mathrm{E}+00$ & 5304 & $0.0 \mathrm{E}+00$ & 7.9 & 2.3 & 64.2 & $\begin{array}{l}\text { nonribosomal peptide } \\
\text { synthase -like protein }\end{array}$ \\
\hline T10094 & $\mathrm{NH}$ & 2132 & - & - & - & - & - & 2.6 & - & - & $\begin{array}{l}\text { bifunctional solanapyrone } \\
\text { synthase }\end{array}$ \\
\hline T6684 & $\mathrm{NH}$ & 1552 & - & 1450 & - & 1789 & $1.1 \mathrm{E}-21$ & 0.8 & 0.6 & 43.2 & $\begin{array}{l}\text { bifunctional solanapyrone } \\
\text { synthase }\end{array}$ \\
\hline T10344 & Bcin03g00060.1 & - & - & - & - & 2083 & $0.0 \mathrm{E}+00$ & - & - & 23.2 & $\begin{array}{l}\text { phenylacetate-CoA ligase } \\
\text { paak }\end{array}$ \\
\hline T253 & Bcin07g00950.1 & 1493 & 4.7E-68 & 1476 & $5.8 \mathrm{E}-68$ & 1474 & $4.2 \mathrm{E}-66$ & 15.4 & 185.9 & 15.9 & short-chain dehydrogenase \\
\hline T9627 & Bcin03g01620.1 & 1643 & $0.0 \mathrm{E}+00$ & 1233 & $0.0 \mathrm{E}+00$ & 1240 & $0.0 \mathrm{E}+00$ & 213.7 & 16.8 & 15.2 & $\begin{array}{l}\text { nad dependent epimerase } \\
\text { protein }\end{array}$ \\
\hline T9913 & $\mathrm{NH}$ & 1385 & - & 461 & - & - & - & 154.2 & 0.8 & - & cinnamoyl-CoA reductase \\
\hline T10102 & $\mathrm{NH}$ & 835 & - & - & - & - & - & 6.1 & - & - & beta-lactamase \\
\hline T10099 & $\mathrm{NH}$ & 2921 & - & - & - & - & - & 4.1 & - & - & $\begin{array}{l}\text { beta-lactamase/transpeptidase } \\
\text {-like protein }\end{array}$ \\
\hline T9539 & Bcin11g02630.1 & 1522 & $1.2 \mathrm{E}-16$ & 1481 & $2.7 \mathrm{E}-16$ & 1398 & $1.8 \mathrm{E}-15$ & 27.4 & 2.9 & 2.9 & $\begin{array}{l}\text { phytanoyl-CoA dioxygenase } \\
\text { family protein }\end{array}$ \\
\hline T9957 & Bcin07g07120.1 & 584 & 7.3E-90 & - & - & - & - & 0.7 & - & - & $\begin{array}{l}\text { enoyl-hydratase isomerase } \\
\text { family protein }\end{array}$ \\
\hline T10360 & Bcin03g00080.1 & - & - & - & - & 1342 & 4.2E-117 & - & - & 34.2 & $\begin{array}{l}\text { taurine catabolism } \\
\text { dioxygenase }\end{array}$ \\
\hline T10358 & Bcin03g00090.1 & - & - & - & - & 2115 & $0.0 \mathrm{E}+00$ & - & - & 43.2 & $\begin{array}{l}\text { taurine catabolism } \\
\text { dioxygenase TauD }\end{array}$ \\
\hline \multicolumn{12}{|c|}{ Oxidation-reduction processes } \\
\hline T9579 & Bcin15g04780.1 & 2025 & $0.0 \mathrm{E}+00$ & 2008 & $0.0 \mathrm{E}+00$ & 1869 & $0.0 \mathrm{E}+00$ & 188.6 & 17.4 & 20.4 & $\begin{array}{l}\text { cytochrome P450 } \\
\text { monooxygenase }\end{array}$ \\
\hline T7866 & Bcin12g04940.1 & 4816 & $0.0 \mathrm{E}+00$ & 5506 & $0.0 \mathrm{E}+00$ & 1741 & $0.0 \mathrm{E}+00$ & 8.3 & 4.8 & 144.9 & $\begin{array}{l}\text { cytochrome P450 } \\
\text { monooxygenase Glic }\end{array}$ \\
\hline T271 & Bcin12g06400.1 & 2729 & $1.7 \mathrm{E}-89$ & 1723 & 3.7E-89 & 2006 & 4.1E-84 & 2.3 & 26.9 & 3.0 & $\begin{array}{l}\text { benzoate 4-monooxygenase } \\
\text { cyt P450 }\end{array}$ \\
\hline T151 & Bin07g05430.1 & - & - & 1917 & $0.0 \mathrm{E}+00$ & 1917 & $0.0 \mathrm{E}+00$ & - & 91.9 & 8.0 & $\begin{array}{l}\text { cytochrome P450 } \\
\text { monooxygenase }\end{array}$ \\
\hline T9563 & Bcin11g00830.1 & 2364 & $0.0 \mathrm{E}+00$ & 2348 & $0.0 \mathrm{E}+00$ & 2064 & $0.0 \mathrm{E}+00$ & 89.5 & 9.0 & 2.5 & flavin-binding monooxygenase \\
\hline T9787 & Bcin08g04930.1 & 3159 & $0.0 \mathrm{E}+00$ & 2405 & $0.0 \mathrm{E}+00$ & 6429 & $0.0 \mathrm{E}+00$ & 51.2 & 1.8 & 4.3 & $\begin{array}{l}\text { flavin-binding monooxygenase } \\
\text {-like protein }\end{array}$ \\
\hline T9590 & $\mathrm{NH}$ & 1899 & - & 246 & - & 241 & - & 3.3 & 0.3 & 0.3 & $\begin{array}{l}\text { fad linked oxidase domain } \\
\text { protein }\end{array}$ \\
\hline T9873 & $\mathrm{NH}$ & 2044 & - & 732 & - & 254 & - & 28.3 & 0.3 & 0.6 & $\begin{array}{l}\text { choline dehydrogenase/alcohol } \\
\text { oxidase }\end{array}$ \\
\hline T10204 & Bcin09g04870.1 & 5827 & 4.5E-04 & - & - & 1888 & $3.2 \mathrm{E}-04$ & 25.7 & - & 2.7 & $\begin{array}{l}\text { SDH assembly factor } \\
\text { mitochondrial }\end{array}$ \\
\hline T9693 & Bcin12g01060.1 & 2089 & $0.0 \mathrm{E}+00$ & 894 & $1.3 \mathrm{E}-138$ & 1435 & $0.0 \mathrm{E}+00$ & 86.5 & 5.2 & 9.5 & $\begin{array}{l}\text { indoleamine 2,3-dioxygenase } \\
\text { beta type }\end{array}$ \\
\hline T10270 & Bcin07g03220.1 & - & - & 728 & $6.9 \mathrm{E}-15$ & - & - & - & 2.2 & - & carbonic anhydrase \\
\hline T212 & Bcin16g02850.1 & 2962 & $0.0 \mathrm{E}+00$ & 3150 & $0.0 \mathrm{E}+00$ & 2336 & $0.0 \mathrm{E}+00$ & 3.0 & 46.5 & 4.1 & $\begin{array}{l}\text { fad binding domain-containing } \\
\text { protein }\end{array}$ \\
\hline
\end{tabular}


Table 5 Differentially expressed transcripts (DETs) identified in Monilinia fructicola (MFRC), Monilinia laxa (MLAX) and Monilinia fructigena (MFRG) (Continued)

\begin{tabular}{|c|c|c|c|c|c|c|c|c|c|c|c|}
\hline \multirow{3}{*}{$\begin{array}{l}\text { Transcript } \\
\text { ID }\end{array}$} & \multirow{3}{*}{$\begin{array}{l}\text { Botrytis cinerea } \\
\text { protein ID }\end{array}$} & \multicolumn{2}{|l|}{ MFRC } & \multicolumn{2}{|l|}{ MLAX } & \multicolumn{2}{|l|}{ MFRG } & \multirow{2}{*}{\multicolumn{3}{|c|}{$\frac{\text { Expression values }}{\text { (RPKM) }}$}} & \multirow{3}{*}{$\begin{array}{l}\text { Putative protein function } \\
\text { (BLASTx) }\end{array}$} \\
\hline & & \multirow{2}{*}{$\begin{array}{l}\text { Contig } \\
\text { size (bp) }\end{array}$} & \multirow{2}{*}{$\begin{array}{l}\text { E-value } \\
\text { (tBLASTn) }\end{array}$} & \multirow{2}{*}{$\begin{array}{l}\text { Contig } \\
\text { size (bp) }\end{array}$} & \multirow{2}{*}{$\begin{array}{l}\text { E-value } \\
\text { (tBLASTn) }\end{array}$} & \multirow{2}{*}{$\begin{array}{l}\text { Contig } \\
\text { size } \\
\text { (bp) }\end{array}$} & \multirow{2}{*}{$\begin{array}{l}\text { E-value } \\
\text { (tBLASTn) }\end{array}$} & & & & \\
\hline & & & & & & & & MFRC & MLAX & MFRG & \\
\hline T9868 & Bcin10g04440.1 & 1193 & $5.0 \mathrm{E}-136$ & - & - & - & - & 262.5 & - & - & SDR family protein \\
\hline T10221 & Bcin14g00490.1 & - & - & 1246 & 4.2E-34 & - & - & - & 8.0 & - & short-chain dehydrogenase \\
\hline T9930 & Bcin01g01090.1 & 203 & $3.0 \mathrm{E}-13$ & 1607 & 7.4E-156 & - & & 0.3 & 3.1 & - & short-chain dehydrogenase \\
\hline T3472 & Bcin02g00280.1 & 1460 & 2.7E-133 & 1953 & $9.8 \mathrm{E}-157$ & 1862 & $9.4 \mathrm{E}-158$ & 1.0 & 1.4 & 13.3 & $\begin{array}{l}\text { fad binding domain- } \\
\text { containing protein }\end{array}$ \\
\hline T4552 & Bcin03g00320.1 & 1989 & $0.0 \mathrm{E}+00$ & 290 & - & 1740 & $0.0 \mathrm{E}+00$ & 1.2 & 1.4 & 64.0 & oxidase \\
\hline T242 & Bcin12g06180.1 & 2314 & $0.0 \mathrm{E}+00$ & 1495 & $0.0 \mathrm{E}+00$ & 1395 & $0.0 \mathrm{E}+00$ & 32.4 & 405.7 & 32.3 & nitrilase/cyanide hydratase \\
\hline $\mathrm{T} 134$ & Bcin13g05670.1 & 1347 & $0.0 \mathrm{E}+00$ & 1329 & $0.0 \mathrm{E}+00$ & 1473 & $0.0 \mathrm{E}+00$ & 29.8 & 698.6 & 52.6 & nitrilase/cyanide hydratase \\
\hline T378 & Bcin01g05790.1 & 3598 & $0.0 \mathrm{E}+00$ & 3508 & $0.0 \mathrm{E}+00$ & 2494 & $0.0 \mathrm{E}+00$ & 11.2 & 91.1 & 8.3 & nitrite reductase \\
\hline \multicolumn{12}{|c|}{ Nucleic acid modification and metabolism } \\
\hline T9754 & Bcin05g02630.1 & 1567 & $0.0 \mathrm{E}+00$ & 2003 & $0.0 \mathrm{E}+00$ & 2430 & $0.0 \mathrm{E}+00$ & 113.2 & 5.3 & 10.5 & zinc ion binding protein \\
\hline T10103 & $\mathrm{NH}$ & 2588 & - & - & - & - & - & 131.5 & - & - & $\begin{array}{l}\text { group II intron reverse } \\
\text { transcriptase/maturase }\end{array}$ \\
\hline T10111 & $\mathrm{NH}$ & 5711 & - & - & - & 2937 & - & 4.0 & - & 80.5 & $\begin{array}{l}\text { group II intron reverse } \\
\text { transcriptase/maturase }\end{array}$ \\
\hline T4409 & BC1G_20011 mito & 510 & - & 214 & - & 4757 & - & 1.4 & 1.6 & 13.2 & group II intron \\
\hline T10367 & Bcin12g04370.1 & - & - & - & - & 4858 & $5.3 \mathrm{E}-73$ & - & - & 29.4 & $\begin{array}{l}\text { retrotransposon polyprotein } \\
\text { (Ty3/Gypsy) }\end{array}$ \\
\hline T10387 & Bcin03g00140.1 & - & - & - & - & 5352 & $0.0 \mathrm{E}+00$ & - & - & 48.2 & $\begin{array}{l}\text { retrotransposon polyprotein } \\
\text { (Ty3/Gypsy) }\end{array}$ \\
\hline T10365 & Bcin10g04500.1 & - & - & - & - & 9377 & $1.0 \mathrm{E}-53$ & - & - & 37.7 & $\begin{array}{l}\text { retrotransposon polyprotein } \\
\text { (Ty3/Gypsy) }\end{array}$ \\
\hline T10350 & Bcin13g03280.1 & - & - & - & - & 4443 & $3.9 \mathrm{E}-29$ & - & - & 625.5 & $\begin{array}{l}\text { retrotransposon polyprotein } \\
\text { (Ty1/Copia) }\end{array}$ \\
\hline T10389 & Bcin09g03840.1 & - & - & 274 & $6.8 \mathrm{E}-26$ & 2191 & $1.4 \mathrm{E}-98$ & - & 0.1 & 4.3 & $\begin{array}{l}\text { retrotransposon polyprotein } \\
\text { (Ty1/Copia) }\end{array}$ \\
\hline T3334 & $\mathrm{NH}$ & - & - & - & - & 737 & - & - & - & 163.6 & $\begin{array}{l}\text { RT from transposon } \\
\text { X-element }\end{array}$ \\
\hline T5170 & Bcin16g02550.1 & - & - & - & - & 1065 & $0.0 \mathrm{E}+00$ & - & - & 150.5 & transposase \\
\hline T10352 & Bcin14g04350.1 & - & - & - & - & 2493 & $5.2 \mathrm{E}-15$ & - & - & 10.3 & $\begin{array}{l}\text { chromo domain containing } \\
\text { protein }\end{array}$ \\
\hline T6826 & Bcin10g02210.1 & - & - & - & - & 802 & $1.1 \mathrm{E}-04$ & - & - & 261.0 & $\begin{array}{l}\text { chromo domain containing } \\
\text { protein }\end{array}$ \\
\hline T91 & $\mathrm{NH}$ & - & - & 4405 & - & - & - & - & 6.4 & - & probable dna polymerase \\
\hline T10215 & Bcin16g04490.1 & - & - & 2149 & $2.4 \mathrm{E}-55$ & - & - & - & 1.5 & - & ribonuclease iii protein \\
\hline T7829 & Bcin03g00050.1 & - & - & - & - & 1759 & $0.0 \mathrm{E}+00$ & - & - & 60.5 & ribonuclease $\mathrm{H}$-like protein \\
\hline Т10342 & Bcin13g01670.1 & - & - & - & - & 1939 & $1.3 \mathrm{E}-96$ & - & - & 3.2 & $\begin{array}{l}\text { trna splicing endonuclease } \\
\text { subunit protein }\end{array}$ \\
\hline \multicolumn{12}{|c|}{ Miscellaneous } \\
\hline T9817 & Bcin12g06170.1 & 1248 & $1.4 \mathrm{E}-122$ & 1658 & $1.5 \mathrm{E}-117$ & 607 & $3.5 \mathrm{E}-58$ & 241.3 & 6.5 & 1.0 & allergen protein \\
\hline T10319 & Bcin13g01080.1 & - & - & - & - & 1891 & $3.6 \mathrm{E}-56$ & - & - & 3.7 & $\begin{array}{l}\text { similar to DUF946 domain } \\
\text {-containing protein }\end{array}$ \\
\hline T10320 & Bcin04g06320.1 & - & - & - & - & 1682 & 4.3E-04 & - & - & 3.3 & $\begin{array}{l}\text { putative heterokaryon } \\
\text { incompatibility protein }\end{array}$ \\
\hline T9635 & $\mathrm{NH}$ & 4825 & - & 682 & - & 331 & - & 11.6 & 0.9 & 1.1 & $\begin{array}{l}\text { HET-domain-containing } \\
\text { protein }\end{array}$ \\
\hline
\end{tabular}


Table 5 Differentially expressed transcripts (DETs) identified in Monilinia fructicola (MFRC), Monilinia laxa (MLAX) and Monilinia fructigena (MFRG) (Continued)

\begin{tabular}{|c|c|c|c|c|c|c|c|c|c|c|c|}
\hline \multirow{3}{*}{$\begin{array}{l}\text { Transcript } \\
\text { ID }\end{array}$} & \multirow{3}{*}{$\begin{array}{l}\text { Botrytis cinerea } \\
\text { protein ID }\end{array}$} & \multicolumn{2}{|l|}{ MFRC } & \multicolumn{2}{|l|}{ MLAX } & \multicolumn{2}{|l|}{ MFRG } & \multirow{2}{*}{\multicolumn{3}{|c|}{$\frac{\text { Expression values }}{\text { (RPKM) }}$}} & \multirow{3}{*}{$\begin{array}{l}\text { Putative protein function } \\
\text { (BLASTx) }\end{array}$} \\
\hline & & \multirow{2}{*}{$\begin{array}{l}\text { Contig } \\
\text { size (bp) }\end{array}$} & \multirow{2}{*}{$\begin{array}{l}\text { E-value } \\
\text { (tBLASTn) }\end{array}$} & \multirow{2}{*}{$\begin{array}{l}\text { Contig } \\
\text { size (bp) }\end{array}$} & \multirow{2}{*}{$\begin{array}{l}\text { E-value } \\
\text { (tBLASTn) }\end{array}$} & \multirow{2}{*}{$\begin{array}{l}\text { Contig } \\
\text { size } \\
\text { (bp) }\end{array}$} & \multirow{2}{*}{$\begin{array}{l}\text { E-value } \\
\text { (tBLASTn) }\end{array}$} & & & & \\
\hline & & & & & & & & $\overline{\text { MFRC }}$ & MLAX & $\overline{M F R G}$ & \\
\hline T326 & Bcin04g00810.1 & - & - & 1446 & $0.0 \mathrm{E}+00$ & - & - & - & 38.2 & - & ankyrin repeat protein \\
\hline T357 & Bcin13g01520.1 & 2371 & $5.4 \mathrm{E}-91$ & 1623 & 3.7E-144 & 586 & 4.1E-94 & 1.4 & 11.8 & 1.1 & $\begin{array}{l}\text { ankyrin repeat-containing } \\
\text { protein }\end{array}$ \\
\hline Т10346 & Bcin01g11420.1 & - & - & - & - & 1019 & $1.2 \mathrm{E}-19$ & - & - & 1.8 & $\begin{array}{l}\text { glutathione S-transferase } \\
\text { protein }\end{array}$ \\
\hline T10278 & Bcin07g01490.1 & - & - & 1982 & $9.3 \mathrm{E}-12$ & 395 & - & - & 2.5 & - & AAA family ATPase \\
\hline T9525 & Bcin07g05160.1 & 6988 & 1.7E-119 & 595 & $1.1 \mathrm{E}-45$ & - & - & 3.3 & 0.4 & - & $\begin{array}{l}\text { HSP mitochondrial precursor } \\
\text { protein }\end{array}$ \\
\hline T9961 & Bcin06g06170.1 & 705 & $1.4 \mathrm{E}-20$ & - & - & - & - & 0.7 & - & - & MmgE/PrpD family protein \\
\hline T9939 & Bcin01g10190.1 & 438 & $7.6 \mathrm{E}-05$ & - & - & - & - & 0.7 & - & - & $\begin{array}{l}\text { BTB/POZ domain-containing } \\
\text { protein }\end{array}$ \\
\hline T9988 & Bcin10g02020.1 & 2167 & $3.1 \mathrm{E}-51$ & - & - & - & - & 4.7 & - & - & $\begin{array}{l}\text { BTB/POZ domain-containing } \\
\text { protein }\end{array}$ \\
\hline T9546 & $\mathrm{NH}$ & 2010 & - & 430 & - & - & - & 3.2 & 0.3 & - & SET domain-containing protein \\
\hline T256 & $\mathrm{NH}$ & 1637 & - & 2277 & - & 537 & - & 2.2 & 26.6 & 0.7 & tldc domain \\
\hline
\end{tabular}

${ }^{¥} \mathrm{NH}=$ No homologs in the $B$. cinerea proteome. Over-expressed transcripts are highlighted in bold

\section{Effector and secreted proteins}

Three DETs were over-expressed in MFRC. A putative protease inhibitor (T9637; $\mathrm{FC}=12.9-39.3)$, containing a phosphatidylethanolamine-binding protein (PEBP) domain, was found. The full-length T9520 (FC = 9.0-11.3) encodes a protein homologous to RHS (rearrangement hotspot)and YD (tyrosine-aspartate)-repeat containing proteins from several fungi (E-value $=0$; id up to 74\%), including $S$. borealis and $B$. cinerea and, with lower similarity (E-value $=0$; id $=32-35 \%$ ), to the type IV secretion protein RHS of Pseudomonas spp.. T9914 ( $\mathrm{FC}=10.1-202.0)$ encodes a secreted trypsin-like serine protease with homologs in the closely related species $B$. cinerea, $S$. sclerotiorum, $S$. borealis (E-value $\leq 4 \mathrm{e}-141 ; \mathrm{id} \geq 83 \%$ ), as well as in other phytopathogenic fungi (e.g., Verticillium, Fusarium and Alternaria spp.) and biocontrol agents (e.g., Trichoderma and Metarhizium spp.) (E-values $\leq 1 \mathrm{e}-57$; id $\geq 54 \%$ ).

In MLAX we found a secreted pepsin-like protein (T144; FC $=15.6-22.3$ ) with a conserved domain for aspergillopepsin-like aspartic proteases and homologs in B. cinerea (BcAP7), S. borealis and other fungi (E-value $\leq 4 \mathrm{e}-93 ; \mathrm{id} \geq 67 \%$ ).

\section{Morphogenesis and development}

Six DETs were significantly over-expressed in MFRC. They included a developmental-specific protein (T9903; $\mathrm{FC}=32.8-148.4$ ), a putative fatty acid elongase (FEN1) of the GNS1/SUR4 family like protein (T9722; FC= 10.1-19.1), and a linoleate 8R-dioxygenase like protein (T9480; $\mathrm{FC}=8.1-14.5$ ) having homology (E-values =0; id 246 ) with psi (producing precocious sexual inducer)-producing oxygenase A (PpoA) from Rhynchosporium, Penicillium and Aspergillus spp.. Two putative cell surface proteins were encoded by T9697 (FC = 16.019.9) and T9572 (FC=9.2-10.0) having homology (E-value $\leq 8 \mathrm{e}-71 ; \mathrm{id} \geq 60 \%$ ) with the Blumeria graminis f.sp. hordei gEgh16 and Egh16H, the M. grisea GAS1 (gEgh16 homologs expressed in Appressorium Stage) and MAS3 (Magnaporthe appressoria specific), and the Colletotrichum CAS1 (appressorium specific protein). T9843 ( $\mathrm{FC}=15.8-58.4$ ) encodes a protein having similarities $(\mathrm{E}$-value $=0$; id $=34-41 \%$ ) with fungal cell wall SED1 proteins.

A putative glycosylphosphatidylinositol-anchored protein (GPI-AP) was significantly over-expressed in MLAX (T205; FC = 15.2-33.5).

\section{Regulation and signalling}

The DETs over-expressed in MFRC included two transcription factors containing a N-terminal GAL4-like $\left(\mathrm{Zn}_{2} \mathrm{Cys}_{6}\right)$ DNA-binding domain (GAL4 TF), T9760 (FC=8.2-21.4) and T9765 (FC=9.6-40.8). T10202 ( $\mathrm{FC}=8.7)$, with no orthologs in MLAX, showed homology (E-value = 2e-119; id $=65 \%$ ) with a $B$. cinerea putative fungal specific TF. Two putative protein kinases (T9641 and T9481) were over-expressed in MFRC ( $\mathrm{FC}=8.6-23.0)$ as well as a putative MSS4 (mammalian suppressor of Sec4) like protein (T9894; FC = 17.5-110.9).

A regulator of $G$ protein signalling (RGS) (T312) was over-expressed in MLAX (FC $=9.2-13.2)$ as well as a protein kinase-like sequence ( $\mathrm{T} 321 ; \mathrm{FC}=9.5)$, with no orthologous 


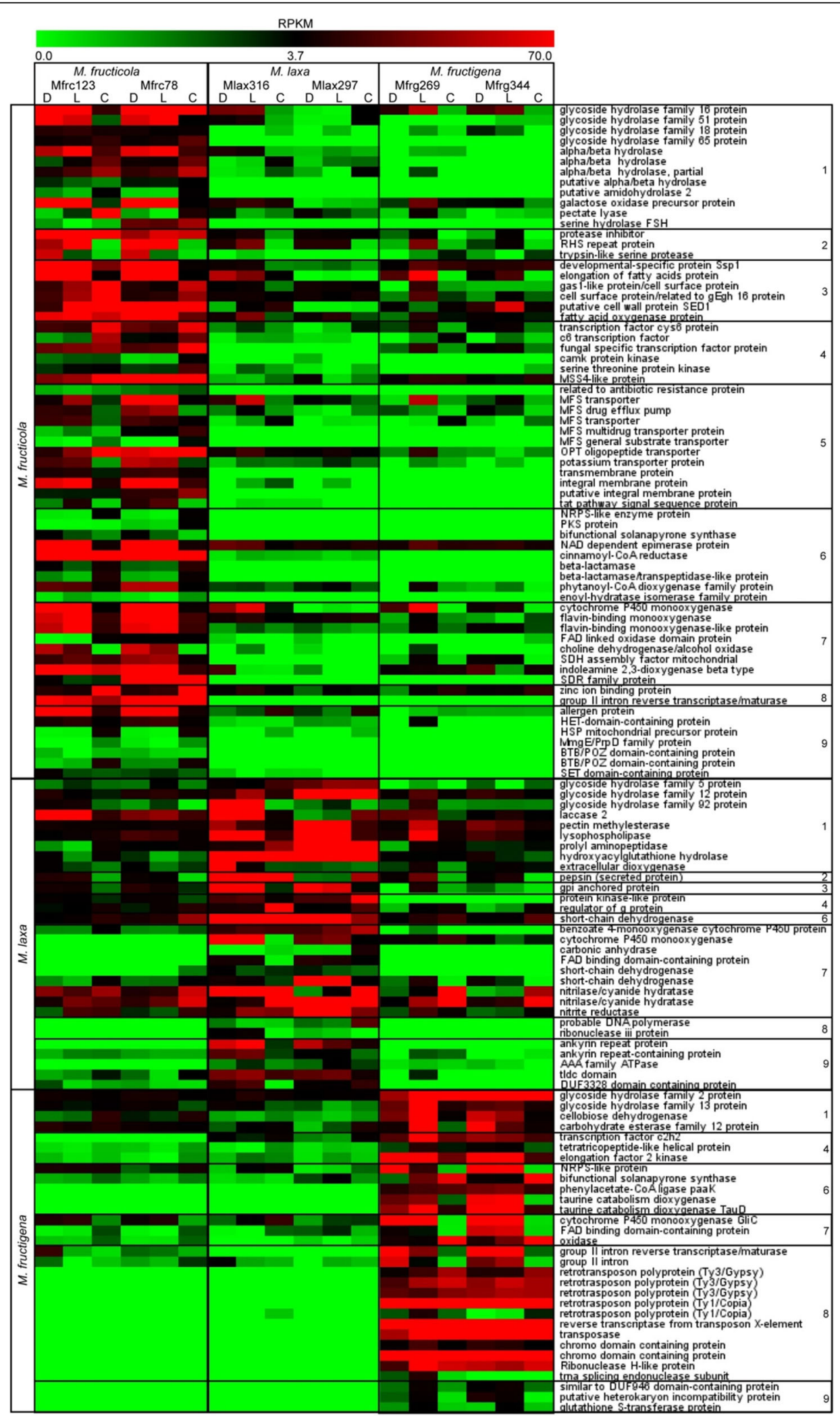

Fig. 5 (See legend on next page.) 
(See figure on previous page.)

Fig. 5 Heat map showing DET expression profiles in samples of mycelium grown in darkness (D) or exposed to light (L) and germinating conidia (C) from two isolates per species. DETS are grouped in functional classes: 1) hydrolytic and carbohydrate-active enzymes; 2) effector and secreted proteins; 3) morphogenesis and development; 4) regulation and signalling; 5) membrane proteins and transport; 6) secondary metabolite biosynthesis; 7) oxidation-reduction processes; 8) nucleic acid modification and metabolism; and 9) miscellaneous

in MFRG, showing homology (E-value $\geq 6 \mathrm{e}-84$; id = 38\%) with phosphotransferases and aminoglycoside phosphotransferases of Aspergillus and Penicillium spp..

A $\mathrm{Zn}$ finger $\mathrm{C} 2 \mathrm{H} 2 \mathrm{TF}$ (T63) was over-expressed in MFRG $(F C=11.7)$, with no orthologs in MFRC. A MFRG elongation factor-2 kinase (eEF-2) (T2642; FC = 109.3-187.4) was fragmented in MFRC and MLAX. T6048 ( $\mathrm{FC}=8.7-10.2$ ) encodes a putative protein with homology $(E-v a l u e=6 e-09$; id $=27 \%)$ with a tetratricopeptide (TPR)-like helical protein of Eutypa lata.

\section{Membrane proteins and transport}

Twelve DETs were over-expressed or unique in MFRC. T10087 encoding a putative major facilitator superfamily (MFS) transporter related to antibiotic resistance proteins from Fusarium spp. (E-value $\geq 1 \mathrm{e}-65$; id up to 50\%), with no homologs in Botrytis and Sclerotinia spp., was reconstructed only in MFRC. The predicted protein contains domains conserved for MFSs and bacterial Bcr/ CflA transporters, which are responsible for drug and antibiotic resistance [24]. Additional MFSs were over-expressed (T9642, T9594 and T9657) or exclusive (T10106 and T10002). T9642 (FC = 13.5-13.8) encodes a MFS protein containing a 4-hydroxyphenylacetate permease domain $\mathrm{HpaX}$, with homology to a $B$. cinerea high-affinity nicotinic acid transporter $(\mathrm{E}$-value $=0.0$; id $=90 \%)$. DETs included an oligopeptide transporter of the OPT family (T9643) and a potassium uptake protein (T9629) (FC = 12.4-35.3). T10105, with no orthologs in MLAX and MFRG, encodes a predicted transmembrane protein, like TLC domain-containing fungal proteins, that may possess multiple functions such as lipid trafficking, metabolism, or sensing. T9893 ( $\mathrm{FC}=120.0)$, partially assembled in MLAX, shows homology with a hypothetical protein of Valsa mali (E-value $=3 \mathrm{e}-101$; id $=44 \%$ ) and integral membrane proteins of Aspergillus and other fungi (E-values $\leq 6 \mathrm{e}-57$; id $=37-40 \%$, with no orthologs in Botrytis and Sclerotinia spp.. T9835 $(\mathrm{FC}=43.5)$, fragmented in MLAX, encodes a putative twin-arginine translocation (Tat) pathway signal sequence protein, with homologs in various fungal species (E-value $=0.0$; id up to $59 \%$ ).

T323 encoding a DUF3328 domain-containing protein, over-expressed in MLAX $(\mathrm{FC}=9.5)$ and partially reconstructed in MFRC, also showed similarity with a Tat pathway signal sequence protein of Rosellinia necatrix $(\mathrm{E}$-value $=1 \mathrm{e}-50$; id $=41 \%)$.

\section{Secondary metabolite (SM) biosynthesis}

T10081 was assembled only in MFRC and showed a low expression level; the encoded protein has a low similarity with a putative non-ribosomal peptide synthetase (NRPS)-like enzyme of $B$. cinerea ( $\mathrm{E}$-value $=9 \mathrm{e}-16$; id $=52 \%$ ). T10004, assembled only in MFRC, was annotated as polyketide synthase (PKS) homologous to BcPKS1 of $B$. cinerea $(\mathrm{E}$-value $=0$; id $=54 \%)$. Three additional DETs, exclusive for MFRC, have homologous genes (E-value $\leq 3 \mathrm{e}-61$; id $\geq 53 \%$ ) on the same $B$. cinerea chromosomic region (chromosome 14: 227,864-247,543) downstream the BcPKS1 gene. They included, in the order: a serine hydrolase (FSH1) domain-containing protein (T9586); a MFS multidrug transporter (T10002); a hypothetical protein (T9288) showing similarities with fungal integral membrane proteins. T10094, assembled only in MFRC, containing D-lactate dehydrogenase and FAD binding domains, showed homology (E-value $\leq 8 \mathrm{e}-65$; id $\geq 47 \%$ ) with a bifunctional solanapyrone synthase of $V$. mali and putative FAD-binding oxidoreductases of several fungal species, such as Talaromyces stipitatus and Alternaria alternata, with no orthologs in Botrytis or Sclerotinia species. The DETs exclusive for MFRC included T10102 exhibiting amino acid similarities to $B$. cinerea $\beta$-lactamases (E-value $\leq 2 \mathrm{e}-07$, id $=34 \%$ and T10099 encoding a putative beta-lactamase/transpeptidase-like protein, containing an AmpC (CubicO group peptidase, beta-lactamase class $\mathrm{C}$ family) domain, with homologs (E-value $\leq 8 \mathrm{e}-34 ; \mathrm{id} \geq 34 \%$ ) in Phialocephala scopiformis and $R$. necatrix. T9627 was over-expressed in MFRC (FC $=12.7-14.1)$ and showed conserved domains for cinnamyl-alcohol dehydrogenase protein family and nucleoside-diphosphate-sugar epimerases. It shares homology with a $B$. cinerea $3-\beta$ hydroxysteroid dehydrogenase/isomerase family protein $(\mathrm{E}-\mathrm{value}=0$; id $=79 \%)$ and with putative dihydroflavonol-4-reductases from different fungi (best $\mathrm{E}$-value $=5 \mathrm{e}-173$; id up to $68 \%$ ). In addition, T9913 encoding a putative cinnamoyl-CoA reductase and containing aldehyde reductase, extended (e) SDRs and NAD-dependent epimerase/dehydratase domains, was highly expressed in MFRC ( $F C=192.8)$, fragmented in MLAX and not detected in MFRG. It has homologs in $S$. borealis (E-value $=0 ; \quad$ id $=82 \%)$ but not in B. cinerea. A putative phytanoyl-CoA dioxygenase (PhyH) family protein (T9539), significantly over-expressed in MFRC $(\mathrm{FC}=9.4)$, with homologs in $S$. borealis, $S$. 
sclerotiorum and B. cinerea (E-value $=0.0 ; \quad$ id $=91-$ 92\%), shares homology with a clavaminate synthase-like protein of Glarea lozoyensis (E-value = $3 \mathrm{e}-152$; id $=70 \%$ ). A putative enoyl-hydratase isomerase family protein containing a transferase domain (T9957) is related to a fumigaclavine B $O$-acetyltransferase-like protein from Acremonium chrysogenum (E-value $=4 \mathrm{e}-34 ; \quad \mathrm{id}=39 \%) \quad$ and to trichothecene 3-O-acetyltransferases from Taphrina deformans and Fusarium spp. (E-values $\leq 7 \mathrm{e}-08 ; \quad$ id $\geq 27 \%)$. A short-chain dehydrogenase/reductase displaying a clavulanic acid dehydrogenase, classical (c) SDR domain (T253) was significantly over-expressed in MLAX (FC $=11.7-12.1)$.

Orthologues of the BcNRPS1, coded T8874, were fragmented in MLAX and over-expressed in MFRG $(\mathrm{FC}=8.1-27.9) \quad$ like $\mathrm{T} 6684 \quad(\mathrm{FC}=54.0-72.0)$, which encodes a protein sharing homology with a FAD-binding-domain containing protein of $S$. borealis (E-value $=0 ; \mathrm{id}=89 \%)$ and bifunctional solanapyrone synthases from Phialophora attae, Diplodia seriata and Penicillium chrysogenum (best E-value $=1 \mathrm{e}-137$; id up to $50 \%$ ). Three transcripts related to secondary metabolism (T10344, T10360 and T10358) were assembled only in MFRG. T10344 encodes a conserved hypothetical protein containing a phenylacetate-coenzyme A (CoA) ligase domain, with homologs in B. cinerea, $S$. borealis and several Penicillium and Aspergillus species (E-value $=0$; id up to $85 \%)$. Two taurine catabolism dioxygenases TauD/TdfA (T10360 and T10358), unique in MFRG and having homologs in B. cinerea, produce sulphite and aminoacetyldehyde from the sulphur-containing amino acid taurine that is used by several bacteria and fungi for growth under sulphate starvation [25]. T10360 exhibits also significant homology (best E-value $=0$; id up to 90\%) with proteins of Penicillium, Aspergillus and other fungi containing a clavaminic acid synthetase (CAS)-like domain.

\section{Oxidation-reduction processes}

A cytochrome P450 monooxygenase (T9579) over-expressed $(F C=9.2-10.8)$ in MFRC shows significant homology with isotrichodermin C-15 hydroxylases (CYP65A1) of Rhynchosporium spp. and Phialocephala subalpine $(\mathrm{E}$-value $=0$; id $=$ 75\%). Two flavin-binding monooxygenase-like proteins, T9563 and T9787, both having homologs in S. borealis, $B$. cinerea and S. sclerotiorum (E-value $=0$; id $\geq 77 \%$ ), were significantly over-expressed in MFRC ( $\mathrm{FC}=9.9-35.8)$.

A benzoate 4-monooxygenase cytochrome $\mathrm{P} 450$ protein (T271), showing homology (best E-values $=2 \mathrm{e}-130$; id up to $43 \%$ ) with fungal trichodiene oxygenases, and a cytochrome P450 monooxygenase (T151) showing similarity to sterigmatocystin biosynthesis $\mathrm{P} 450$ monooxygenases of Aspergillus niger and Colletotrichum chlorophyti (best $\mathrm{E}$-value $=4 \mathrm{e}-131$; id up to $45 \%)$ were over-expressed in
MLAX ( $F C=9.0-11.5)$, like two nitrilase/cyanide hydratases (T242 and T134; FC $=12.5-23.4)$ and a putative nitrite reductase ( $\mathrm{T} 378 ; \mathrm{FC}=8.1-11.0$ ).

A cytochrome P450 monooxygenase (T7866), having homologs in S. sclerotiorum, B. cinerea and S. borealis $($ E-value $=0$; id $\geq 89 \%)$ and showing similarity $(E$-value $=0)$ to trichodiene oxygenase cytochrome P450 of Fusarium spp. (id up to 55\%) and GliC proteins of Aspergillus spp. (id up to 64\%), was over-expressed in MFRG (FC= 17.5-30.2).

\section{Nucleic acid modification and metabolism}

A zinc ion binding protein (T9754) containing a WLM (WSS1-like metalloprotease) domain was over-expressed in MFRC ( $F C=10.8-21.4)$; it is related to the DNA damage response proteins WSS1 involved in sister chromatid separation and segregation and shares homology with $B$. cinerea and $S$. borealis proteins (e-values $=0$; $\mathrm{id} \geq 77 \%$ ). In addition, a group II intron reverse transcriptase/maturase (T10103), with homologs in Neurospora intermedia (E-value $=1 \mathrm{e}-40$; id $=32 \%$ ) and other fungi but not Sclerotiniaceae, was uniquely assembled in MFRC.

A mitochondrial DNA polymerase type B protein (T91) was uniquely assembled in MLAX, as well as a ribonuclease III (RNAse III) protein (T10215).

A mitochondrial group II intron encoding a multifunctional protein, belonging to the LAGLIDADG family of homing endonucleases (T4409) was assembled only in MFRG while short fragments were reconstructed in MFRC and MLAX. A group II intron reverse transcriptase/maturase (T10111), over-expressed in MFRG $(F C=20.1)$ and assembled in MFRC, has a homolog in Juglanconis oblonga (E-value $=0$; id $=52 \%$ ). Several transcripts related to retroelements were generally identified as unique in MFRG. In detail, T10367 and T10387 encode polyproteins with conserved domains of reverse transcriptase (RT) and ribonuclease $H$ (RNase $H$ ) enzymes from long terminal repeats (LTRs) retroelements of the Ty3/Gypsy family, sharing homology with proteins from $B$. cinerea and other fungi (E-values $=0$; id $\geq 46 \%)$. Related to the same family is a polyprotein containing RT, RNase $\mathrm{H}$ and retropepsin domains (T10365) with homologs in S. sclerotiorum (e-value =0: id up to $62 \%$ ). T10350 encodes a polyprotein with RT and RNase $\mathrm{H}$ domains from LTRs retroelements of the Tyl/ Copia family with a homolog in S. borealis (E-value = $7 e-119 ;$ id $=66 \%$ ). T10389 encodes a retrotransposon protein with a gag-polypeptide of LTRs Copia-like domain, with a homolog in B. cinerea (E-value $=1 \mathrm{e}-97$; id $=62 \%$ ). Both LTRs Copia-like retrotransposons showed similarity to retrovirus-related Pol polyproteins from the plant transposon TNT 1-94 (best E-value $=1 \mathrm{e}-75$; id up to $37 \%$ ). T3334 is a partial sequence of a putative non-LTRs retrotransposon 
having homology with RNA-directed DNA polymerase from fungal transposon X-elements (E-value $=2 \mathrm{e}-77$; id $=63 \%$ ) of the Long INterspersed Elements (LINE) class. T5170 encodes a transposase of the DDE superfamily endonuclease with homologs in $B$. cinerea and S. sclerotiorum (E-value $=0$; id up to $99 \%$ ). Two chromo (CHRromatin Organisation MOdifier) domain containing proteins were identified: T10352 with similarity to a putative gag polymerase env protein of B. cinerea (E-value $=4 \mathrm{e}-27 ; \quad$ id $=72 \%) ; \mathrm{T} 6826$ with similarity to truncated Pol $(\mathrm{E}$-value $=3 \mathrm{e}-43$; id $=85 \%)$ and BRTN (E-value $=2 \mathrm{e}-29$; id $=63 \%$ ) from Boty-like retrotransposons of $B$. cinerea. A putative RNA exoribonuclease 3 (REX3) (T7829) with a homolog in $B$. cinerea (E-value $=0$; id $=80 \%$ ), contains a $3^{\prime}-5^{\prime}$ exonuclease domain belonging to the DEDDh protein superfamily.

\section{Miscellaneous}

Among DETs over-expressed in MFRC we found an allergen protein (T9817; FC $=37.1-241.3$ ) sharing homology with a peptide transport protein of Aureobasidium pullulans (E-value $=1 \mathrm{e}-73$; id $=65 \%$ ) and a dehydrin-like protein $2 \mathrm{~b}$ of $A$. alternata (E-value $=1 \mathrm{e}-59$; $\mathrm{id}=57 \%$ ). T9635 encode a HET-domain-containing protein fully reconstructed in MFRC and fragmented in MLAX and MFRG. T9525, encoding a putative heat shock protein (HSP) mitochondrial precursor with homologs in S. borealis, S. sclerotiorum and B. cinerea (E-value $\leq 1 \mathrm{e}-111$; id $\geq 50 \%$ ), was assembled in MFRC, fragmented in MLAX and absent in MFRG.

T326, uniquely assembled in MLAX, and T357, over-expressed $(\mathrm{FC}=8.4-10.7)$, encode putative ankyrin repeat proteins. T10278, fully assembled in MLAX and partially in MFRG, encodes a putative ATPase of the AAA family.

T10319, unique in MFRG, showed homology with a putative DUF946 domain-containing $B$. cinerea protein $(\mathrm{E}$-value $=2 \mathrm{e}-54 ; \quad \mathrm{id}=49 \%) \quad$ and the vacuolar sorting-associated protein 62 (VPS62) of Ophiocordyceps sinensis $(\mathrm{E}$-value $=1 \mathrm{e}-46$; id $=45 \%)$. T10320 was assembled only in MFRG and showed homology with HET-domain-containing proteins (best E-value $=0$; id up to $73 \%$ ). T10346 assembled only in MFRG encodes a protein with homology to the $B$. cinerea glutathione S-transferase BcGST22 (E-value $=1.2 \mathrm{e}-19 ; \quad$ id $=45 \%)$ likely involved in detoxification of xenobiotics.

\section{Discussion}

The complete transcriptomes of MFRC, MLAX and MFRG were reconstructed and annotated. Comparative analyses among orthologous transcripts revealed 65 transcripts over-expressed $(\mathrm{FC} \geq 8$ and $\mathrm{FDR} \leq 0.05)$ or unique for MFRC, 30 in MLAX and 31 in MFRG.
DETs encoding hydrolytic or carbohydrate-active enzymes were identified; nine were $\mathrm{GHs}$, each belonging to a different family according to the Carbohydrate-Active Enzymes database (CAZy) classification (http://www.cazy.org/Glycoside-Hydrolases.html), which represent the largest and most diverse family of biopolymer-degrading enzymes [26].

The GHs over-expressed in MFRC included a $\beta$-1,3-glucan binding protein that in Phanerochaete chrysosporium is involved in the degradation of laminarin [27]; an $\alpha$-L-arabinofuranosidase which is homolog to the Magnaporthe oryzae MoAbfB required for full virulence and inducing host defence responses [28]; and a chitin-binding type 1 protein. Effector proteins with chitin binding activity are directly involved in pathogenic processes in Cladosporium fulvum, M. oryzae and Mycosphaerella graminicola [29] and along with chitinases are up-regulated during $S$. sclerotiorum infection on Brassica napus [30]. Pizzuolo et al. [6] compared isolates of MFRC, MLAX and MFRG for pectolytic activity and their isoenzyme patterns and reported no substantial differences in the production of pectolytic enzymes (i.e. pectin methylesterase, polygalacturonase and pectin lyase) useful to differentiate the three species. In our study, two enzymes involved in plant cell wall breakdown were highly over-expressed in MFRC: a pectate lyase and a galactose oxidase, which is a secreted enzyme well characterized in Fusarium spp. catalysing the oxidation of D-galactose and other primary alcohols to aldehydes with concomitant reduction of molecular oxygen to hydrogen peroxide [31]. Moreover, two GAL4 TFs, over-expressed in MFRC, are positive regulators for galactose-induced genes in S. cerevisiae and for genes encoding enzymes degrading plant cell-wall polysaccharides in pathogenic fungi. The GAL4 TF encoded by the AbPf2 (Alternaria brassicicola pathogenicity factor 2) gene is essential for the pathogenicity of the fungus [32]. Several $\alpha / \beta$ hydrolases, including proteins with carboxylesterase and lipase activities, and a putative amidohydrolase were over-expressed or uniquely assembled in MFRC. Amidohydrolases catalyse the hydrolysis of a wide range of substrates bearing amide or ester functional groups and include ß-lactamases, e.g. penicillin amidohydrolase involved in antibiotic metabolism [33].

The DETs over-expressed in MLAX included plant cell-wall degrading enzymes, such as a pectin methylesterase, a ß-1,6-galactanase protein (GH5), a xyloglucan-specific endo- $\beta-1,4$-glucanase (GH12) and an $\alpha-1,2$-mannosidase (GH92). Furthermore, other over-expressed enzymes were identified, such as a lysophospholipase, virulence factors in fungal pathogens [30], an hydroxyacylglutathione hydrolase, also known as glyoxalase II, involved in detoxification of methylglyoxal and related toxicants generated from the 
degradation of glycolytic products [34], and a putative extracellular intradiol dioxygenase belonging to an enzyme family catalysing ring cleavage of catecholate derivatives and likely involved in lignin breakdown [35].

GHs over-expressed in MFRG include a putative $\alpha$-amylase (GH13) acting on $\alpha$-glycosidic bonds and involved in lignocellulose saccharification processes [36] and a B-mannosidase B-like protein (GH2), enzymes displaying different substrate specificity in Aspergillus spp. that likely reflect the diversity of their functions [37]. Two additional cell-wall degrading enzymes were identified, a carbohydrate esterase family 12 protein, acting on pectin, and a cellobiose dehydrogenase which plays a key role during pathogenesis in Sclerotium species [38] and in lignocellulose degradation by wood-rotting fungi [39].

A protease inhibitor containing a PEBP domain was over-expressed in MFRC. The yeast PEBP homologue TFS1 is supposed to be a bridge between cell signalling and intermediate metabolism in Saccharomyces cerevisiae [40]. Protease inhibitors are fungal effectors involved in plant-pathogen interactions; e.g., the inhibitor encoded by the C. fulvum avirulence gene Avr2 is secreted during tomato infection and acts on papain-like cysteine proteases involved in plant defence [41]. We also identified in MFRC an RHS repeat protein. This class of proteins includes secreted bacterial insecticidal and nematocidal toxins and intercellular signalling proteins mediating bacterial-host or bacterial-bacterial interactions (e.g., [42]) A different class of the same family includes the Ss-RHS1 secretory protein from $S$. sclerotiorum that is related to sclerotial development, appressoria differentiation and virulence [43]. A trypsin-like serine protease was over-expressed in MFRC while a secreted pepsin-like aspartic proteases was over-expressed in MLAX. Trypsin-related enzymes are supposed to play a specific role in pathogenicity since they are the major proteases produced by plant-pathogenic Verticillium spp. whereas there are no reports of trypsins being secreted by saprophytes [44]. Secreted aspartic proteases, commonly known as acid proteases, are endopeptidases involved in functions related to nutrition and pathogenesis [45].

Among DETs related to fungal morphogenesis and development, we found over-expressed in MFRC a developmental-specific protein homolog to the S. sclerotiorum sclerotium-specific protein (Ssp1) detected in all stages of sclerotium and apothecium development [46]. A phenotypic comparison among the three Monilinia species described in a recent study by Villarino et al. [7] showed that sclerotia and stromata differentiation, affecting fungal survival under unfavourable conditions, was the most important factor distinguishing MFRC from the other two species. Moreover, MFRC is described as able to produce apothecia from pseudosclerotia in mummified fruit under both natural and in vitro conditions [47]; further functional studies are needed to determine the role of Ssp1 homologous gene in pseudosclerotia development and evolution of Monilinia spp.. MFRC is also characterized by a faster colony growth and more abundant sporulation than MLAX and MFRG [5, 7]. In this study, MFRC showed over-expression of a fatty acid oxygenase with homology to PpoA proteins which are cyclooxygenase-like enzymes responsible for oxylipin production and regulate the development of conidiophores and cleistothecia and the production of toxic metabolites and degradative enzymes affecting fungal development and plant-pathogen interactions [48]. Other DETs were over-expressed in MFRC: a MSS4-like protein playing a role in cell polarization, polar tip extension and hyphal growth in Neurospora crassa [49]; a fatty acid elongase (FEN1) involved in sphingolipid biosynthesis and in modulation of resistance to amphothericin B in yeasts [50]; and the SED1 protein which is believed involved in resistance to lytic enzymes. Besides, two MFRC cell surface proteins are homologous to the Blumeria graminis f.sp. hordei gEgh16 and Egh16H, M. grisea GAS1 and MAS3, and Colletotrichum CAS1, all virulence factors essential for the establishment of plant-pathogen interactions [51].

DETs over-expressed in MLAX include a GPI anchored protein, important for cell wall synthesis and integrity in $N$. crassa [52] and implicated in virulence and in planta proliferation in Fusarium graminearum [53]; a regulator of $\mathrm{G}$ protein signalling which play key roles in upstream regulation of fundamental processes in fungi, including vegetative growth, sporulation, mycotoxin and pigment production, pathogenicity and mating [54]; two ankyrin repeat proteins, mediating protein-protein interactions; and a putative ATPase of the AAA family, a large and diverse group of enzymes inducing conformational changes in a wide range of proteins associated with cell-cycle regulation, proteolysis, organelle biogenesis and intracellular transport [55].

A Ca2+/calmodulin-dependent (CaMK) and a serine/ threonine protein kinases were over-expressed in MFRC while a protein kinase-like over-expressed in MLAX shares homology with phosphotransferases responsible for antibiotic resistance in Aspergillus and Penicillium spp. [56].

A $\mathrm{Zn}$ finger $\mathrm{C} 2 \mathrm{H} 2$ TF was over-expressed in MFRG. Such TFs are involved in pathogenicity, catabolite repression, acetamide regulation, differentiation of fruiting body, as well as stress responses and multidrug resistance in yeasts and human fungal pathogens. In $B$. cinerea they are involved in phytotoxin biosynthesis, secondary metabolism, carbohydrate metabolism, transport, virulence and detoxification mechanisms $[57,58]$. MFRG also showed over-expression of TPR-like helical protein involved in stress and hormone signalling in plants [59]. 
The full-length transcript of an HSP mitochondrial precursor was reconstructed in MFRC. HSPs are involved in various biological processes and play crucial roles in morphogenetic changes, stress adaptation and antifungal resistance [60].

Several transmembrane transporters were over-expressed or exclusive for MFRC: MFS transporters that are involved, like the ATP-binding cassette (ABC) transporters, in multidrug resistance to natural and synthetic toxicants and playing a key role in plant pathogens as a shield against plant defence compounds during the pathogenesis and in fungicide resistance [61]; two flavin-binding monooxygenase-like proteins with $\mathrm{CzcO}$ conserved domain associated with the cation diffusion facilitator $\mathrm{CzcD}$, which are involved in metal tolerance or resistance [62]; and a putative signal sequence protein of the Tat secretion pathway that serves to actively translocate fully folded proteins across membranes [63].

The most common SMs in fungi are polyketides, terpenoids and shikimic acid-derived compounds. PKSs and NRPSs are key enzymes in the biosynthesis of SMs containing highly conserved functional domains. The corresponding genes in fungal genomes are frequently co-localized and co-expressed with other genes coding for other enzymes involved in the same biosynthetic pathway [64]. Bifunctional solanapyrone synthases, over-expressed in both MFRC and MFRG, are involved in the biosynthesis of the polyketide-derived phytotoxins solanapyrones in Alternaria solani, Ascochyta rabiei and other fungi. Their phytotoxicity is well documented but their contribution to the pathogenicity has been questioned, while antifungal activity against microorganic competitors has been reported during saprotrophic but not parasitic growth [65]. $\beta$-lactamase transcripts were reconstructed in MFRC. Bacterial $\beta$-lactamases are known to confer resistance to $\beta$-lactam antibiotics, while the fungal homologs have been supposed to be responsible for the degradation of plant or microbial lactam compounds; for instance, a $\beta$-lactamase-containing gene cluster (FDB1) of Fusarium verticillioides confers resistance to lactam phytoanticipins [66]. A phenylacetate-CoA ligase was reconstructed in MFRG. Enzymes of this family are involved in the degradation pathway of aromatic compounds and in the biosynthesis of the $\beta$-lactam antibiotic penicillin G in P. chrysogenum [67]. In MFRC we also found a highly expressed putative cinnamoyl-CoA reductase, enzymes that in plants are involved in the phenylpropanoid biosynthetic pathway and have homologues in some bacteria and fungi although lacking the full pathway [68]. Several DETs are involved in the biosynthesis of clavulanic acid, a potent inhibitor of bacterial class A serine $\beta$-lactamases, with weak antibiotic activity. The clavaminic acid synthetase (CAS) and clavulanic acid dehydrogenase (CAD) are involved in its biosynthesis [69]. The PhyH protein identified in MFRC shares homology with a CAS-like protein of the human fungal pathogen Glarea lozoyensis; a putative CAD protein was over-expressed in MLAX; and the TauD unique in MFRG exhibits significant homology to CAS-domain-containing proteins of Penicillium, Aspergillus and other fungi. Moreover, a PhyH protein coded by the thnG gene from Streptomyces cattleya is involved in the biosynthesis of the $\beta$-lactam antibiotic thienamycin [70].

Several DETs were involved in mycotoxin metabolism. In MFRC a putative enoyl-hydratase isomerase containing a transferase domain showed similarity with the fumigaclavine B $O$-acetyltransferase involved in the biosynthesis of fumigaclavine $\mathrm{C}$, an ergot alkaloid produced by fungi of the Trichocomaceae family [71] and with the trichothecene 3-O-acetyltransferases from Fusarium spp., which modify the trichothecene mycotoxin deoxynivalenol (DON) and reduce its toxicity [72], while a cytochrome $\mathrm{P} 450$ monooxygenase is related to isotrichodermin C-15 hydroxylases involved in the biosynthesis of trichothecenes [73]. DETs identified in MLAX included a benzoate 4-monooxygenase cytochrome P450 protein homologous to fungal trichodiene oxygenases, like the Fusarium sporotrichioides Tri4, involved in the trichothecene biosynthesis [74], and a cytochrome P450 monooxygenase showing similarity to enzymes essential for the synthesis of the polyketide-derived mycotoxin sterigmatocystin [75]. DETs identified in MFRG included a cytochrome $\mathrm{P} 450$ monooxygenase sharing similarity with enzymes that in Fusarium spp. and Aspergillus spp. are involved in the biosynthesis of the trichothecene and gliotoxin [76].

Differences in detoxification mechanisms were observed. The glutathione S-transferase assembled in MFRG is likely involved in detoxification of xenobiotics. Two nitrilases/cyanide hydratases were highly expressed in MLAX. Phytopathogenic fungi use nitrilases/cyanide hydratase to detoxify cyanide or cyanide by-products generated by plants, like amygdalin and prunasin produced by stone fruits which contribute to defence against herbivores and fungal pathogens [77].

Group II introns were detected in MFRC and MFRG. In bacterial genome and eukaryotic organelles, they are supposed to be an ancient class of ribozymes and mobile retroelements using intron-encoded reverse transcriptase, maturase and DNA endonuclease activities for site-specific insertion into homologous intron-less alleles [78]. Several transcripts related to LTR retroelements of the Ty3/Gypsy and the Ty1/Copia families were generally identified as unique in MFRG, revealing an active retrotransposition in the pathogen genome.

An RNAse III protein was uniquely assembled in MLAX. Eukaryotic RNase III or RNase III like enzymes, such as Dicer, are involved in RNAi (RNA interference) and miRNA (micro-RNA) gene silencing [79]. 


\section{Conclusions}

In this study, we provide the first large-scale reconstruction and annotation of the transcriptomes of the phytopathogenic fungi MFRC, MLAX and MFRG which are the main causes of heavy yield losses on pome and stone fruits all around the world. The assembled transcriptomes included about 30,000 transcripts per species that were mostly complete, with low to moderate levels of duplication, fragmentation and estimated missing transcripts. About 50\% of transcripts were functionally annotated. The transcriptomes of the three Monilinia species did not show any significant differences in the GO and OG cluster functional categories. Consequently, orthologous transcripts were identified in the three species on the base of the $B$. cinerea proteome and, additionally, more than 400 transcripts specific for at least one of the Monilinia species with no homologs in the reference were detected. A comparative analysis among orthologs in the three species based on transcript abundance revealed DETs over-expressed or exclusive for each of the three species. They were mostly associated with biopolymer-degrading enzymatic activities, detoxifying activity, secondary metabolism, such as biosynthesis and metabolism of xenobiotics, i.e. antibiotics and toxins, as well as processes affecting fungal morphogenesis and development, diversity and pathogen interactions with the host plants and the microbiotes.

Biopolymer-degrading enzymes, which are frequently pathogenicity factors, were more numerous in MFRC and MLAX than in MFRG. They included effectors, such as a chitin-binding protein, and enzymes involved in antibiotic metabolism in MFRC, and a methylglyoxal detoxifying enzyme in MLAX. Secreted proteins related to pathogenicity were detected, like a pepsin-like protein in MLAX and a trypsin-related enzyme in MFRC which displays also a putative protease inhibitor acting as effector during pathogenesis. These results are consistent with previous findings displaying less aggressiveness components of MFRG compared to MFRC and MLAX, in terms of lesions and incubation and latency period on artificially inoculated nectarine fruit at postharvest [7]. Moreover, MFRC was characterised by a very high expression of the developmental-specific protein Ssp1, cell surface proteins acting as virulence factors, enzymes responsible for oxylipin production and regulation of spore differentiation and plant-pathogen interactions, a MSS4-like protein playing a role in apical hyphal growth, numerous MFS transporters related to pathogenesis and multidrug resistance, enzymes involved in the biosynthesis of antimicrobials (solanapyrone, clavulanic acid) and mycotoxins, and $\beta$-lactamases involved in antimicrobial resistance. MLAX was characterised by enzymes responsible for antibiotic resistance, CAD enzymes involved in clavulanic acid biosynthesis, a P450 protein putatively involved in biosynthesis of mycotoxins, and cyanide hydratases detoxifying cyanogenic compounds which are typically produced by stone fruit trees. MFRG was characterised by a glutathione $\mathrm{S}$-transferase involved in detoxification of xenobiotics, solanapyrone synthases, and enzymes involved in the biosynthesis of $\beta$-lactam antibiotics, clavulanic acid and gliotoxin-like mycotoxins. The fungus displayed numerous DETs related to transposable elements indicating an intense transposition activity in its genome.

The genes differentially expressed in the three pathogens play relevant roles in morphogenesis and development, diversity and pathogenesis and are worthwhile of further investigations since they might explain their different fitness. The data obtained represent new insights in the transcriptome analyses of the three species of Monilinia and provide a new and comprehensive genetic resource that will contribute to get deeper knowledge on the population biology, physiology and plant-pathogen interactions of these important phytopathogenic fungi which are essential for improving sustainable crop protection strategies.

\section{Additional file}

Additional file 1: Table S1. Summary of sequencing data. Table S2. Numbers of mapping reads on the Monilinia fructicola (MFRC), $M$. laxa (MLAX) and M. fructigena (MFRG) assembled transcriptomes. (DOCX $51 \mathrm{~kb})$

\section{Abbreviations}

CAD: clavulanic acid dehydrogenase; CAS: clavaminic acid synthetase; CoA: coenzyme A; DET: differentially expressed transcript;

EggNog: Evolutionary genealogy of genes: Non-supervised Orthologous Groups; FC: Fold Change; FDR: False Discovery Rate; GH: glycoside hydrolase; GO: Gene Ontology; GPI: glycosylphosphatidylinositol; HSP: heat shock protein; LTR: Iong terminal repeat; MFRC: Monilinia fructicola; MFRG: Monilinia fructigena; MFS: major facilitator superfamily; MLAX: Monilinia laxa; MSS4: mammalian suppressor of Sec4; NRPS: non-ribosomal peptide synthetase; OG: orthologous group; ORF: Open Reading Frame;" PEBP: phosphatidylethanolamine-binding protein; $\mathrm{PhyH}$ : phytanoyl-CoA dioxygenase; PKS: polyketide synthase; RGS: regulator of G protein signalling; RHS: rearrangement hotspot; RNase: ribonuclease; RPKM: reads per Kb of transcript per million mapped reads; RT: reverse transcriptase; SM: secondary metabolites; Tat: twin-arginine translocation; TF: transcription factor; TPR: tetratricopeptide repeat

\section{Acknowledgements}

The Monilinia fructigena strain Mfrg344 was kindly supplied by Prof. Marta Mari, Department of Agricultural Sciences, University of Bologna, Italy. Bioinformatic analysis was partially carried out by using the facilities of the ReCaS data center of the University of Bari (www.recas-bari.it).

\section{Funding}

The research was partially carried out in the framework of the project "Epidemiology, genetics of plant pathogens and development of molecular diagnostic methods" granted by the University of Bari. The PhD course of Domenico Abate was granted by Sumitomo Chemical Italia. The funding company had no role in the design of the study and collection, analysis, and interpretation of data and in writing the manuscript. 


\section{Availability of data and materials}

Data generated in this study are publicly available from the NCBI/GenBank database at Bioproject ID PRJNA419302. All raw sequence data have been deposited in the Sequence Read Archive (https://www.ncbi.nlm.nih.gov/ Traces/study/?acc=SRP125382) under the accession number SRR63121736312190. The Transcriptome Shotgun Assembly projects have been deposited at DDBJ/EMBL/GenBank (https://www.ncbi.nlm.nih.gov/Traces/ wgs) under the accessions GGAK00000000 (MFRC), GGAL00000000 (MLAX) and GGAM00000000 (MFRG). The versions described in this paper are the first versions, GGAK01000000 (MFRC), GGAL01000000 (MLAX), GGAM01000000 (MFRG)

\section{Authors' contributions}

RMDMA designed and performed the experiments, analysed the data, and supervised and complemented the writing; DA performed the experiments, analysed the data, and wrote the article; CR performed some experiments and analysed part of data; DG performed some experiments and analysed part of data; SP designed the experiments and supervised the writing; FF designed the experiments, supervised and complemented the writing and coordinated the collaboration of the authors. All authors have read and approved the final manuscript.

\section{Ethics approval and consent to participate}

The Monilinia isolates used in this study were stored in the fungal collection of the Department of Soil, Plant and Food Sciences - Plant Pathology Section of the University of Bari (Italy). No permits were required for the collection of the fungal samples.

\section{Competing interests}

The authors declare that they have no competing interests.

\section{Publisher's Note}

Springer Nature remains neutral with regard to jurisdictional claims in published maps and institutional affiliations.

\section{Received: 29 November 2017 Accepted: 22 May 2018}

\section{Published online: 05 June 2018}

\section{References}

1. Oliveira Lino L, Pacheco I, Mercier V, Faoro F, Bassi D, Bornard I, QuilotTurion B. Brown rot strikes Prunus fruit: an ancient fight almost always lost. J Agric Food Chem. 2016;64:4029-47.

2. Rungjindamai $N$, Jeffries $P, X u X M$. Epidemiology and Management of brown rot on stone fruit caused by Monilinia laxa. Eur J Plant Pathol 2014;140:1-17.

3. Villarino M, Egüen B, Lamarca N, Segarra J, Usall J, Melgarejo P, De Cal A. Occurrence of Monilinia laxa and $M$. fructigena after introduction of $M$. fructicola in peach orchards in Spain. Eur J Plant Pathol. 2013;137:835-45.

4. Datasheets CABI. Monilinia fructicola (brown rot). Invasive Species Compendium. 2017; https://www.cabi.org/isc/datasheet/34746. Accessed 16 Nov 2017

5. Abate D, Pastore C, Gerin D, De Miccolis Angelini RM, Rotolo C, Pollastro S, Faretra F. Characterization of Monilinia spp. populations on stone fruits in South Italy. Plant Dis. 2018; https://doi.org/10.1094/PDIS-08-17-1314-RE.

6. Pizzuolo PH, Chilosi G, Balmas V, Aleandri MP, Vitale S, Luongo L, et al. Variations in the molecular and physiological characteristics and the virulence of Monilinia fructicola, M. fructigena and M laxa isolates Phytopathol Mediterr. 2006; https://doi.org/10.1400/54737.

7. Villarino M, Melgarejo P, Growth DCA. Aggressiveness factors affecting Monilinia spp. survival peaches Int J Food Microbiol. 2016;224:22-7.

8. Fulton CE, Van Leeuwen GCM, Brown AE. Genetic variation among and within Monilinia species causing brown rot of stone and pome fruits. Eur J Plant Pathol. 1999;105:495-500.

9. loos R, Frey P. Genomic variation within Monilinia laxa, M. fructigena and M. fructicola, and application to species identification by PCR. Eur J Plant Pathol. 2000;106:373-8

10. Jänsch M, Frey JE, Hilber-Bodmer M, Broggini GAL, Weger J, Schnabel G, Patocchi A. SSR marker analysis of Monilinia fructicola from Swiss apricots suggests introduction of the pathogen from neighbouring countries and the United States. Plant Pathol. 2012;61:247-54.
11. Villarino M, Larena I, Martinez F, Melgarejo P, De Cal A. Analysis of genetic diversity in Monilinia fructicola from the Ebro Valley in Spain using ISSR and RAPD markers. Eur J Plant Pathol. 2012;132:511-24.

12. Hily JM, Singer SD, Villani SM, Cox KD. Characterization of the cytochrome $b$ (cyt b) gene from Monilinia species causing brown rot of stone and pome fruit and its significance in the development of Qol resistance. Pest Manag Sci. 2011;67:385-96.

13. Lee MH, Chiu CM, Roubtsova T, Chou CM, Bostock RM. Overexpression of a redox-regulated cutinase gene, MFCUT1, increases virulence of the brown rot pathogen Monilinia fructicola on Prunus spp. Mol Plant-Microbe Interact. 2010;23:176-86.

14. Abate D, De Miccolis Angelini RM, Rotolo C, Pollastro S, Faretra F. Mating system in the brown rot pathogens Monilinia fructicola, Monilinia laxa and Monilinia fructigena. Phytopathology. 2018; https://doi.org/10.1094/PHYTO03-18-0074-R.

15. Bolger AM, Lohse M, Usadel B. Trimmomatic: a flexible trimmer for Illumina sequence data. Bioinformatics. 2014;30:2114-20.

16. Haas BJ, Papanicolaou A, Yassour M, Grabherr M, Blood PD, Bowden J, et al. De novo transcript sequence reconstruction from RNA-seq using the trinity platform for reference generation and analysis. Nat Protoc. 2013:8:1494-512.

17. Camacho C, Coulouris G, Avagyan V, Ma N, Papadopoulos J, Bealer K, Madden TL. BLAST+: architecture and applications. BMC Bioinformatics. 2009;10:421.

18. Conesa A, Götz S, García-Gómez JM, Terol J, Talón M, Robles M. Blast2GO: a universal tool for annotation, visualization and analysis in functional genomics research. Bioinformatics. 2005;21:3674-6.

19. Simão FA, Waterhouse RM, loannidis P, Kriventseva EV, Zdobnov EM. BUSCO: assessing genome assembly and annotation completeness with single-copy orthologs. Bioinformatics. 2015;31:3210-2.

20. Robinson MD, McCarthy DJ, Smyth GK. edgeR: a Bioconductor package for differential expression analysis of digital gene expression data. Bioinformatics. 2010;26:139-40.

21. Yang $Y$, Smith SA. Optimizing de novo assembly of short-read RNA-seq data for phylogenomics. BMC Genomics. 2013;14:328.

22. Ye J, Fang L, Zheng H, Zhang Y, Chen J, Zhang Z, et al. WEGO: a web tool for plotting GO annotations. Nucleic Acids Res. 2006;34:W293-7.

23. Huerta-Cepas J, Szklarczyk D, Forslund K, Cook H, Heller D, Walter MC, et al. eggNOG 4.5: a hierarchical orthology framework with improved functional annotations for eukaryotic, prokaryotic and viral sequences. Nucleic Acids Res. 2016:44:D286-93.

24. Marklevitz J, Harris LK. Prediction driven functional annotation of hypothetical proteins in the major facilitator superfamily of $S$. aureus NCTC 8325. Bioinformation. 2016;12:254-62

25. Yew SM, Chan CL, Kuan CS, Toh YF, Ngeow YF, Na SL, et al. The genome of newly classified Ochroconis mirabilis: insights into fungal adaptation to different living conditions. BMC Genomics. 2016;17:91.

26. Murphy C, Powlowski J, Wu M, Butler G, Tsang A. Curation of characterized glycoside hydrolases of fungal origin. Database (Oxford). 2011;2011 bar020

27. Kawai R, Igarashi K, Yoshida M, Kitaoka M, Samejima M. Hydrolysis of $\beta-1,3$ / 1,6-glucan by glycoside hydrolase family 16 endo-1,3(4)- $\beta$-glucanase from the basidiomycete Phanerochaete chrysosporium. Appl Microbiol Biotechnol. 2006;71:898-906.

28. Wu J, Wang Y, Park SY, Kim SG, Yoo JS, Park S, et al. Secreted alpha-NArabinofuranosidase $B$ protein is required for the full virulence of Magnaporthe oryzae and triggers host Defences. PLoS One. 2016;11 e0165149

29. Sánchez-Vallet A, Saleem-Batcha R, Kombrink A, Hansen G, Valkenburg DJ, Thomma BP, Mesters JR. Fungal effector Ecp6 outcompetes host immune receptor for chitin binding through intrachain LysM dimerization elife 2013:2 e00790

30. Seifbarghi S, Borhan MH, Wei Y, Coutu C, Robinson SJ, Hegedus DD. Changes in the Sclerotinia sclerotiorum transcriptome during infection of Brassica napus. BMC Genomics. 2017;18:266.

31. Paukner R, Staudigl P, Choosri W, Sygmund C, Halada P, Haltrich D, Leitner C. Galactose oxidase from Fusarium oxysporum - expression in E. coli and $P$. pastoris and biochemical characterization. PLoS One. 2014;9:e100116.

32. Cho Y, Ohm RA, Grigoriev IV, Srivastava A. Fungal-specific transcription factor AbPf2 activates pathogenicity in Alternaria brassicicola. Plant J. 2013;75:498-514.

33. Alvarez E, Meesschaert B, Montenegro E, Gutiérrez S, Díez B, Barredo J L Martín JF. The isopenicillin-N acyltransferase of Penicillium chrysogenum has 
isopenicillin- $\mathrm{N}$ amidohydrolase, 6-aminopenicillanic acid acyltransferase and penicillin amidase activities, all of which are encoded by the single penDE gene. Eur J Biochem. 1993;215:323-32.

34. Kalapos MP. Methylglyoxal in living organisms. chemistry, biochemistry, toxicology and biological implications Toxicol Lett. 1999;110:145-75.

35. Rieble S, Joshi DK, Gold MH. Purification and characterization of a 1,2,4trihydroxybenzene 1,2-dioxygenase from the basidiomycete Phanerochaete chrysosporium. J Bacteriol. 1994;176:4838-44.

36. Jiménez DJ, de Lima Brossi MJ, Schückel J, Kračun SK, Willats WG, van Elsas JD. Characterization of three plant biomass-degrading microbial consortia by metagenomics- and metasecretomics-based approaches. Appl Microbiol Biotechnol. 2016;100:10463-77.

37. Reddy SK, Rosengren A, Klaubauf S, Kulkarni T, Karlsson EN, de Vries RP, Stålbrand $\mathrm{H}$. Phylogenetic analysis and substrate specificity of $\mathrm{GH} 2 \beta$ mannosidases from Aspergillus species. FEBS Lett. 2013;587:3444-9.

38. Ludwig R, Haltrich D. Cellobiose dehydrogenase production by Sclerotium species pathogenic to plants. Lett Appl Microbiol. 2002;35:261-6.

39. Dumonceaux T, Bartholomew K, Valeanu L, Charles T, Archibald F. Cellobiose dehydrogenase is essential for wood invasion and nonessential for Kraft pulp delignification by Trametes versicolor. Enzym Microb Technol. 2001:29:478-89.

40. Beaufour M, Godin F, Vallée B, Cadene M, Bénédetti $H$. Interaction proteomics suggests a new role for the Tfs 1 protein in yeast. J Proteome Res. 2012;11:3211-8.

41. Shabab M, Shindo T, Gu C, Kaschani F, Pansuriya T, Chintha R, et al. Fungal effector protein AVR2 targets diversifying defense-related cys proteases of tomato. Plant Cell. 2008;20:1169-83.

42. Koskiniemi S, Lamoureux JG, Nikolakakis KC. t'Kint de Roodenbeke C, Kaplan MD, low DA, Hayes CS. Rhs proteins from diverse bacteria mediate intercellular competition. Proc Natl Acad Sci U S A. 2013;110:7032-7.

43. Yu Y, Xiao J, Zhu W, Yang Y, Mei J, Bi C, et al. Ss-Rhs1, a secretory Rhs repeat containing protein, is required for the virulence of Sclerotinia sclerotiorum. Mol Plant Pathol. 2017;18:1052-61.

44. St Leger RJ, Joshi L, Roberts DW. Adaptation of proteases and carbohydrates of saprophytic, phytopathogenic and entomopathogenic fungi to the requirements of their ecological niches. Microbiology. 1997;143:1983-92.

45. ten Have A, Espino JJ, Dekkers E, Van Sluyter SC, Brito N, Kay J, González C, van Kan JA. The Botrytis cinerea aspartic proteinase family. Fungal Genet Biol. 2010;47:53-65.

46. Li M, Rollins JA. The development-specific protein (Ssp1) from Sclerotinia sclerotiorum is encoded by a novel gene expressed exclusively in sclerotium tissues. Mycologia. 2009;101:34-43.

47. De Cal A, Egüen B, Melgarejo P. Vegetative compatibility groups and sexua reproduction among Spanish Monilinia fructicola isolates obtained from peach and nectarine orchards, but not Monilinia laxa. Fungal Biol. 2014;118:484-94.

48. Fischer GJ, Keller NP. Production of cross-kingdom oxylipins by pathogenic fungi: an update on their role in development and pathogenicity. J Microbiol. 2016;54:254-64.

49. Mähs A, Ischebeck T, Heilig Y, Stenzel I, Hempel F, Seiler S, Heilmann I. The essential phosphoinositide kinase MSS-4 is required for polar hyphal morphogenesis, localizing to sites of growth and cell fusion in Neurospora crassa. PLoS One. 2012;7:e51454.

50. Sharma S, Alfatah M, Bari VK, Rawal Y, Paul S, Ganesan K. Sphingolipid biosynthetic pathway genes FEN1 and SUR4 modulate amphotericin B resistance. Antimicrob Agents and Chemother. 2014;58:2409-14.

51. Grell MN, Mouritzen P, Giese H. A Blumeria graminis gene family encoding proteins with a C-terminal variable region with homologues in pathogenic fungi. Gene. 2003;311:181-92

52. Bowman SM, Piwowar A, Al Dabbous M, Vierula J, Free SJ. Mutational analysis of the glycosylphosphatidylinositol (GPI) anchor pathway demonstrates that GPI-anchored proteins are required for cell wall biogenesis and normal hyphal growth in Neurospora crassa. Eukaryot Cell. 2006:5:587-600

53. Rittenour WR, Harris SD. Glycosylphosphatidylinositol-anchored proteins in Fusarium graminearum: inventory, variability, and virulence. PLoS One. 2013; 8(11):e81603.

54. Wang $Y$, Geng Z, Jiang D, Long F, Zhao Y, Su H, Yang J. Characterizations and functions of regulator of $G$ protein signaling (RGS) in fungi. Appl Microbiol Biotechnol. 2013;97:7977-87.

55. Hanson PI, Whiteheart SW. AAA+ proteins: have engine, will work. Nat Rev Mol Cell Biol. 2005;6:519-29.
56. Mingeot-Leclercq MP, Glupczynski Y, Tulkens PM. Aminoglycosides: Activity and resistance. Antimicrob Agents Chemother. 1999:43:727-37.

57. MacPherson S, Larochelle M, Turcotte B. A fungal family of transcriptional regulators: the zinc cluster proteins. Microbiol Mol Biol Rev. 2006;70:583-604.

58. Simon A, Dalmais B, Morgant G, Viaud M. Screening of a Botrytis cinerea one-hybrid library reveals a Cys 2 his 2 transcription factor involved in the regulation of secondary metabolism gene clusters. Fungal Genet Bio. 2013;52:9-19.

59. Rosado A, Schapire AL, Bressan RA, Harfouche AL, Hasegawa PM, Valpuesta $V$, Botella MA. The Arabidopsis tetratricopeptide repeatcontaining protein $\Pi \mathrm{TL} 1$ is required for osmotic stress responses and abscisic acid sensitivity. Plant Physiol. 2006;142:1113-26.

60. Tiwari S, Thakur R, Shankar J. Role of heat-shock proteins in cellular function and in the biology of Fungi. Biotechnol Res Int. 2015; https://doi.org/10. 1155/2015/132635.

61. Perlin MH, Andrews J, Toh SS. Essential letters in the fungal alphabet. ABC and MFS transporters and their roles in survival and pathogenicity Adv Genet. 2014;85:201-53.

62. Kolaj-Robin O, Russell D, Hayes KA, Pembroke JT, Soulimane T. Cation diffusion facilitator family: structure and function. FEBS Lett. 2015;589:1283-95.

63. Wickner W, Schekman R. Protein translocation across biological membranes. Science. 2005;310:1452-6.

64. Pusztahelyi T, Holb IJ, Pócsi I. Secondary metabolites in fungus-plant interactions. Front Plant Sci. 2015;6:573.

65. Kim W, Park JJ, Dugan FM, Peever TL, Gang DR, Vandemark G, Chen W. Production of the antibiotic secondary metabolite solanapyrone a by the fungal plant pathogen Ascochyta rabiei during fruiting body formation in saprobic growth. Environ Microbiol. 2017;19:1822-35.

66. Gao M, Glenn AE, Blacutt AA, Gold SE. Fungal lactamases: their occurrence and function. Front Microbiol. 2017;8:1775.

67. Koetsier MJ, Jekel PA, van den Berg MA, Bovenberg RA, Janssen DB. Characterization of a phenylacetate-CoA ligase from Penicillium chrysogenum. Biochem J. 2009;417:467-76.

68. Emiliani G, Fondi M, Fani R, Gribaldo S. A horizontal gene transfer at the origin of phenylpropanoid metabolism: a key adaptation of plants to land. Biol Direct. 2009:4:7.

69. Tahlan K, Anders C, Jensen SE. The paralogous pairs of genes involved in clavulanic acid and clavam metabolite biosynthesis are differently regulated in Streptomyces clavuligerus. J Bacteriol. 2004;186:6286-97.

70. Rodríguez M, Núñez LE, Braña AF, Méndez C, Salas JA, Blanco G. Mutational analysis of the thienamycin biosynthetic gene cluster from Streptomyces cattleya. Antimicrob Agents Chemother. 2011;55:1638-49.

71. Liu X, Wang L, Steffan N, Yin WB, Li SM. Ergot alkaloid biosynthesis in Aspergillus fumigatus: FgaAT catalyses the acetylation of fumigaclavine B. Chembiochem. 2009:10:2325-8.

72. Khatibi PA, Newmister SA, Rayment I, McCormick SP, Alexander NJ, Schmale DG. Bioprospecting for trichothecene 3-O-acetyltransferases in the fungal genus Fusarium yields functional enzymes with different abilities to modify the mycotoxin deoxynivalenol. Appl Environ Microbiol. 2011;77:1162-70.

73. Alexander NJ, Hohn TM, McCormick SP. The TR/11 gene of Fusarium sporotrichioides encodes a cytochrome P-450 monooxygenase required for C-15 hydroxylation in trichothecene biosynthesis. Appl Environ Microbiol. 1998;64:221-5.

74. Hohn TM, Desjardins AE, McCormick SP. The Tri4 gene of Fusarium sporotrichioides encodes a cytochrome P450 monooxygenase involved in trichothecene biosynthesis. Mol Gen Genet. 1995;248:95-102.

75. Keller NP, Watanabe CM, Kelkar HS, Adams TH, Townsend CA. Requirement of monooxygenase-mediated steps for sterigmatocystin biosynthesis by Aspergillus nidulans. Appl Environ Microbiol. 2000;66:359-62.

76. Kupfahl C, Michalka A, Lass-Flörl C, Fischer G, Haase G, Ruppert T, et al. Gliotoxin production by clinical and environmental Aspergillus fumigatus strains. Int J Med Microbiol. 2008:298:319-27.

77. O'Reilly C, Turner PD. The nitrilase family of CN hydrolysing enzymes - a comparative study. J Appl Microbiol. 2003;95:1161-74.

78. Mullineux ST, Costa M, Bassi GS, Michel F, Hausner G. A group II intron encodes a functional LAGLIDADG homing endonuclease and self-splices under moderate temperature and ionic conditions. RNA. 2010;16:1818-31.

79. Carmell MA, Hannon GJ. RNase III enzymes and the initiation of gene silencing. Nat Struct Mol Biol. 2004;11:214-8. 